\title{
NIVELES DE POTENCIALIDAD TURÍSTICA EN EL LITORAL MEXICANO SITUADO ENTRE CABO CORRIENTES, JALISCO Y POCHUTLA, OAXACA
}

\author{
Oscar Reyes Pérez* \\ Universidad Autónoma de San Luis Potosí \\ http://orcid.org/0000-0002-1433-9887 \\ Xochizeltzin Castañeda Camacho** \\ The University of Texas at Austin \\ http://orcid.org/0000-0003-3312-3974 \\ José Guadalupe Rivera González*** \\ Universidad Autónoma de San Luis Potosí \\ http://orcid.org/0000-0002-2108-3963 \\ Mayra Elizabeth Quiroz Acosta**** \\ Universidad Autónoma de San Luis Potosí \\ http://orcid.org/0000-0001-9588-714X
}

\section{RESUMEN}

En tan sólo 19 años del presente siglo, el turismo global ha alcanzado el mayor dinamismo que en ningún otro período había tenido. Al respecto, entre 2008 y 2017se incrementó en $33.7 \%$ la llegada de turistas internacionales, lo cual ha hecho evidente la necesidad de abrir nuevos mercados turísticos. En el caso de México, de 2009 a 2018 el número de turistas internacionales prácticamente se duplicó; de hecho, en estos años el país avanzó del décimo al sexto destino en el mundo. En este contexto, el gobierno reconoce que, en materia de economía, el turismo es pieza clave para el desarrollo nacional, por tanto, establece como prioridad la identificación de nuevos sitios para el ocio y la recreación. Este trabajo evalúa la potencialidad turística de los municipios costeros del Pacífico Sur occidental mexicano; región que se extiende por el litoral ubicado entre los estados de Jalisco y Oaxaca.

Fecha de recepción: 12 de octubre 2018.

Fecha de aceptación: 20 de septiembre de 2019.

* Facultad de Ciencias Sociales y Humanidades. Universidad Autónoma de San Luis Potosí. Av. Industrias 101-A. Col. Talleres, CP. 78399. SAN LUIS POTOSÍ (México). E-mail: osrp@uaslp.mx

** Department of Geography \& the Environment. The University of Texas at Austin. 305 E 23rd Street. A3100 Austin. TEXAS 78712 (Estados Unidos). E-mail: xochizeltzin@utexas.edu

****E-mail: joserivera@uaslp.mx

*****E-mail: Mati_may11@hotmail.com 
Palabras clave: Potencial turístico; tipificación probabilística; teoría; metodología; región costera; México.

\title{
Tourist potential levels in the Mexican coast located between Cabo Corrientes, Jalisco and Pochutla, Oaxaca
}

\begin{abstract}
In just 19 years of this century, global tourism has reached the greatest dynamism levels relative to any other equivalent period of time. In this regard, the arrival of international tourists showed a $33.7 \%$ rise between 2008 and 2017, evidencing the need to open up new tourist markets. In the case of Mexico, the number of international tourists almost doubled between 2009 and 2018; in fact, in this period, the country advanced from a 10th to sixth top destination worldwide. In this context, the government has acknowledged that, in the field of economy, tourism is key for national development; therefore, it has set the identification of new sites for leisure and recreation as a top priority. This work evaluates the tourist potential of the coastal municipalities of the Mexican southwestern Pacific, a region that stretches along the coastline between the states of Jalisco and Oaxaca.
\end{abstract}

Keywords: Tourism potential; probabilistic classification; theory; methodology; coastal region, Mexico.

\section{INTRODUCCIÓN}

Con más de 11,000 kilómetros de litoral, México forma parte de los 15 países con mayor relevancia en márgenes costeros; de hecho, entre las naciones que en América conforman la vertiente del Pacífico, ocupa el segundo lugar después de Chile (Ortiz y De la Lanza, 2006, pp. 3-12). A su vez, de los 1,528 kilómetros de línea costera frontal correspondiente a la región Pacífico Sur Occidental comprendida entre Bahía de Banderas, en Jalisco y Pochutla, en Oaxaca, representan el 15\% del total nacional y el $20 \%$ del Pacífico Mexicano; valores que desde el punto de vista regional y, en términos de longitud, convierten a esta área en una de las más importantes para el país, aunque debe reconocerse que es de las menos documentadas (Figura 1).

Esta región se ubica en el litoral de los estados de Jalisco, Colima, Michoacán, Guerrero y Oaxaca; por ello, sus límites son: al norte, con la Sierra Madre del Sur; al noroeste, con Bahía de Banderas en Jalisco; al oeste y sur, con el Océano Pacífico; y al sureste, con la localidad de Mazunte en Oaxaca (Ortiz y De la Lanza, 2006, p. 25). Para este trabajo, desde un punto de vista político administrativo en relación con procesos naturales, sociales y económicos, fueron considerados 32 municipios: desde Cabo Corrientes en Jalisco, hasta Pochutla en Oaxaca (Figura 1).

La relevancia de la región costera del Pacífico Sur Occidental Mexicano, desde una perspectiva histórico-cultural, se remonta a principios del siglo $\mathrm{XV}$, cuando formó parte de la unidad cultural denominada Mesoamérica; de hecho, para el año 1400 d.C., en el área que actualmente corresponde al estado de Guerrero existió el centro urbano de Zacatula, 


\section{Figura 1 \\ UBICACIÓN DE LA REGIÓN COSTERA DEL PACÍFICO SUR OCCIDENTAL MEXICANO}

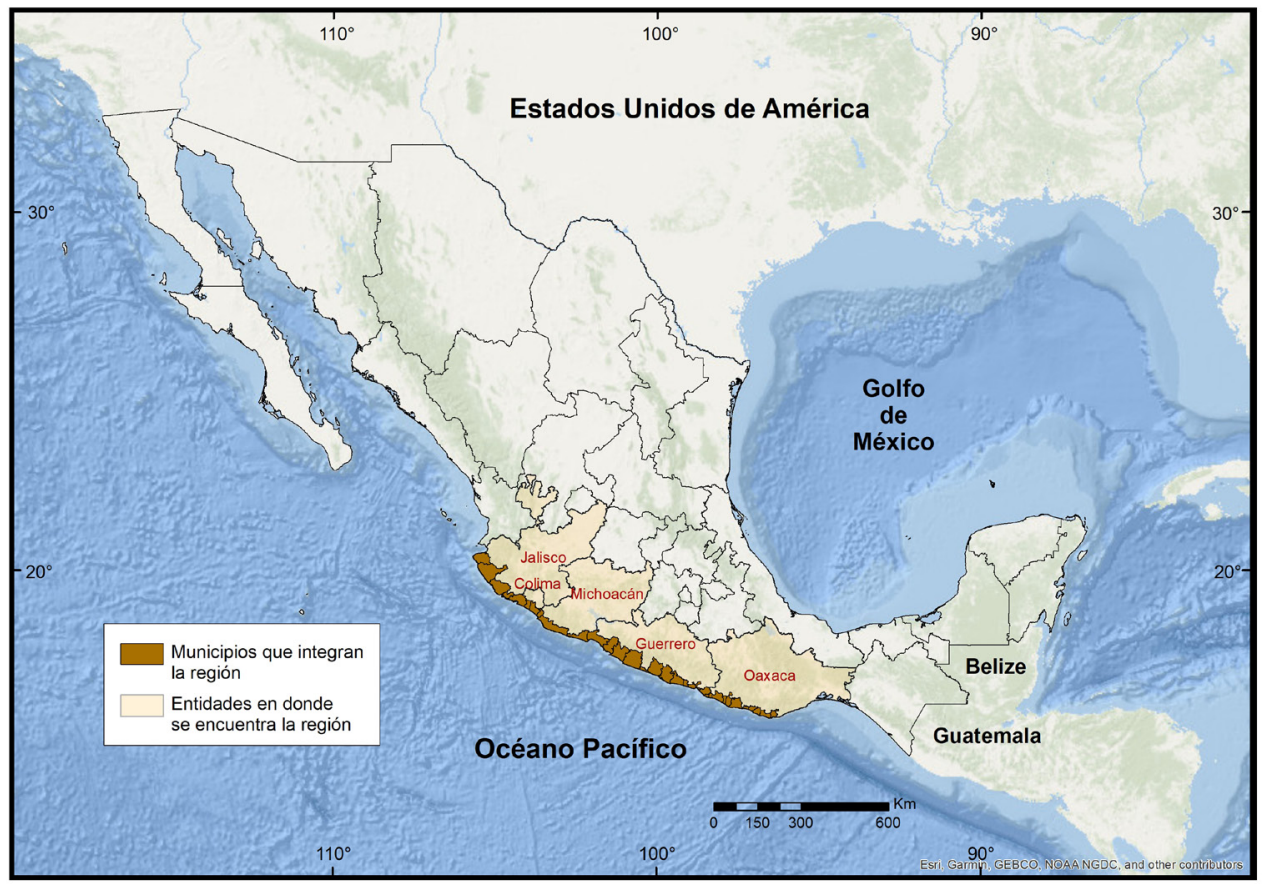

Fuente: Elaboración propia con base en Conabio 2003 y 2010.

uno de los primeros asentamientos del señorío indígena de Yopitzingo (Garza y Jiménez, 2007). Más tarde, a principios del siglo XVI, debido a la expansión territorial de la Triple Alianza ${ }^{1}$, del señorío de Michoacán y de unidades políticas primarias y secundarias de Occidente, el número y tamaño de las localidades fue en aumento, entre ellas, Mexcaltepec, Salagua, Tututepec, Cabrel e Ixtapa (Garza et al., 2007).

Posteriormente, como territorio de la Nueva España, debido al auge minero auspiciado en la Colonia, florecieron las ciudades o poblaciones de Navidad, Manzanillo, Zacatula, Acapulco y Tututepec (Paredes, 2007). En el caso de los puertos de Acapulco y Huatulco, la dinámica comercial fue el factor determinante. Es importante mencionar que la producción industrial, consistente en obrajes, prosperó en la costa del actual estado de Michoacán (Tamayo et al, 2007).

En la segunda mitad del siglo XX, esta porción de la República Mexicana comenzó a destacar en la economía nacional debido al crecimiento de importantes complejos de ocio y recreación que atrajeron el interés de visitantes nacionales y extranjeros. Al respecto, en

1 Estuvo integrada por la unión de las ciudades o centros de poder indígena de Tenochtitlan, Tlacopan y Texcoco. 
el decenio de los cincuenta, Acapulco cobró fama al recibir personalidades del cine estadounidense; en el caso de Puerto Escondido, sus atributos naturales, entre ellos sus playas y el mar, fueron conocidos por turistas que pudieron transitar entre Oaxaca y Guerrero con la construcción en 1960 de la carretera costera 200; en tanto, en 1974, debido a los recursos proporcionados por el Banco de México como parte de la política en torno a la planificación de centros turísticos, comenzaron las obras en Ixtapa Zihuatanejo.

En pleno siglo XXI, la región es escenario de diversos procesos demográficos y económicos inherentes a un país cuya economía descansa en el aprovechamiento de sus recursos energéticos, en las remesas provenientes de los migrantes mexicanos que laboran en Estados Unidos, la afluencia turística proveniente de diversas regiones del mundo y sobre una endeble dinámica productiva del sector agropecuario, forestal y pesquero. Por otra parte, la vinculación de dicha región hacia el interior del país se ha fortalecido por los ejes carreteros que, por un lado, comunican a las localidades adyacentes a la costa y, por el otro, conectan a los principales centros urbanos con las ciudades de Guadalajara, Morelia y la capital del país.

En lo que va del presente siglo, la política económica de México en materia de turismo ha estado enfocada en atraer un mayor número de visitantes, de diversificar los mercados turísticos, de la integración de la población local en el desarrollo de la actividad y de un crecimiento bajo una visión de sustentabilidad. Estas directrices se advierten en el objetivo 4.11 del Plan Nacional de Desarrollo 2013-2018que a letra dice“ Aprovechar el potencial turístico de México para generar una mayor derrama” (Gobierno de la República, 2013: 143) y en el Programa Sectorial de Turismo 2013-2018 que al alinearse con las metas nacionales definió como objetivo "Transformar el sector turístico y fortalecer esquemas de colaboración y corresponsabilidad para aprovechar el potencial turístico" (Diario Oficial, 2013).

Esta visión en el sexenio del presidente Enrique Peña Nieto estuvo sustentada ante el hecho de queel $87 \%$ de la población en municipios turísticos de México tenía un nivel de marginación "muy bajo", y que ese porcentaje disminuía a $9 \%$ en municipios donde esta actividad no estaba presente. Además, según este estudio, el país al posicionarse de forma adecuada en el segmento de sol y playa, permitiría obtener una mayor derrama económica en otras de sus variantes, por ejemplo, el turismo cultural, ecoturismo y aventura, de salud, deportivo, de lujo, de negocios y reuniones o de cruceros(Gobierno de la República, 2013).

En la actualidad, en busca de lo que se ha denominado como la Cuarta Transformación de México, el gobierno federal en la formulación de la Estrategia Nacional de Turismo 2019 - 2024,considera que el modelo turístico debe ser justo, transparente, equilibrado, responsable, distributivo y ejemplar, pues a partir de estas directrices se podrá:

"Posicionar a México como una potencia turística competitiva y de vanguardia que haga del turismo un pilar para el desarrollo justo y equilibrado entre comunidades y regiones, así como una herramienta de reconciliación social, mediante el aprovechamiento sustentable del patrimonio turístico nacional" (Gobierno de México y SECTUR, 2019: 24)

Con base en lo anterior, este trabajo partió de tres aseveraciones: la primera enuncia que la riqueza natural y cultural existente en esta porción del litoral mexicano posee las 
condiciones necesarias para incrementar la dinámica de la actividad turística; la segunda, reconoce que los habitantes de la región deben ser, a través del empoderamiento, actores principales de este proceso; la última, postula que toda iniciativa a implementarse debe elaborarse con base en los criterios de la sustentabilidad ambiental. Por tanto, la pertinencia de esta investigación responde a la visión social, económica y ambiental del gobierno federal toda vez que, en materia de turismo, éste considera dos hechos: por un lado, que el turismo representa un medio para generar empleo e incrementar los mercados donde operan pequeñas y medianas empresas; por el otro, que esta actividad económica al ser instrumentada de modo conveniente favorece la preservación de la riqueza natural y cultural.

\section{NOCIONES TEÓRICAS Y CONCEPTUALES DE LA INVESTIGACIÓN}

Según la Real Academia Española (RAE), el potencial es visto como aquella cosa "que tiene la virtud o eficacia de otras y equivale a ellas", en materia de turismo se utiliza como un término que hace alusión a sitios con determinadas características que propicianen personas que viven en otros lugares un interés por conocerlos (Gallardo, 2013 y Román et al. 2017). Sin embargo, en los trabajos hechos en torno al potencial turístico, se advierte la carencia de fundamentos que permitan delimitar qué es y en aquellos documentos donde se plantean, sólo se da un esbozo conceptual.

En relación con lo anterior, para México, la Secretaría de Turismo, con la finalidad de respaldar los planes estratégicos de desarrollo de inicios del siglo XXI, realizó un estudio de las regiones y los municipios del país para destacar sus atributos que permitan el desarrollo de la actividad turística; para tal fin, esta dependencia de gobierno consideró que el potencial turístico "lo determina la forma en que la oferta de productos y servicios turísticos de una localidad se adapta para satisfacer las necesidades actuales de esparcimiento y recreación de los turistas nacionales e internacionales" (SECTUR, 2005). En el caso de Chile, Faúndez (2013: 2) para evaluar el patrimonio natural del Glaciar El Morado y las Termas del Plomo, situados en el Cajón del Maipo de la Provincia Cordillera, Región Metropolitana, consideró al "Potencial Turístico de un lugar como la máxima cantidad de visitantes que él puede atraer en un tiempo determinado". Ahora bien, aunque se reconoce que existe poca literatura que se ha ocupado de definir al potencial turístico, algunos autores han hecho aportaciones significativas. En este sentido, Mikery y Pérez (2014), en una búsqueda para delimitar este término, encontraron que adquiere las interpretaciones siguientes:

- Según Glăvan (2006) es "la suma de posibilidades de que el ambiente natural y social pone a disposición las actividades turísticas"

- Para Ielenicz y Comănescu (2009) consiste en "una suma de recursos naturales y humanos"

- En cuanto a Muntele y Iațu (2006), el potencial turístico es "lo máximo posible a lograr"

En una investigación sobre los recursos y destinos turísticos en Rumania, Neacsu et al (2016: 13)plantearon que el potencial turístico debe definirse como "el conjunto de los componentes naturales, histórico-cultural, socio-demográfico y técnico-económico, cien- 
tíficamente reconocido, cuantitativo y cualitativo y probado como oportunidades para la capitalización del turismo y dando alguna funcionalidad para el turismo".

En un estudio más específico, el caso del cantón Pasaje, provincia de El Oro, Ecuador, Lazo et al. (2017: 4) consideraron que "el potencial turístico de un territorio radica en su capacidad de atracción de turistas y satisfacción de sus necesidades, se establece la necesidad de dotar a los atractivos de instalaciones e infraestructuras necesarias para la realización actividades turísticas". En este contexto, los autores sugirieron que "antes de iniciar cualquier actividad económica relacionada con el turismo es imperativo determinar su situación actual, a través de índices y factores claves para el desarrollo turístico"; es decir, desarrollar las metodologías necesarias para tal propósito.

Con base en este orden de ideas, para este documento se asume al potencial turístico del territorio comoel conjunto de elementos físico-naturales y humanos (sociales, culturales, políticos y económicos) que posee un espacio geográfico determinado, que puede generar la afluencia de visitantes provenientes de diferentes escalas geográficas, que proporciona las condiciones propicias para el ocio y la recreación y que suele motivar un interés por regresar.

Como puede deducirse de lo anterior, el potencial turístico del territorio, sin que sea algo exclusivo, si conlleva una connotación eminentemente económica. Por tal razón, con base en la visión de Strauss (1972: 8) que considera la potencialidad económica de los recursos naturales (en este caso también los culturales) como "el producto que podría obtenerse de una unidad de recurso natural aplicando una determinada cantidad de capital y mano de obra; en otras palabras, expresaría la productividad potencial del capital y de la mano de obra empleados en la explotación del recurso", en esta investigación se consideraron los factores que según este autor inciden en el aumento o disminución de potencialidad económica, y que son los siguientes:

- "Sus cualidades intrínsecas establecen directamente la potencialidad física o técnica.

- Su accesibilidad o situación con respecto al espacio económico actual, y en particular, a la infraestructura de transportes.

- Su situación con referencia a otros recursos naturales de los cuales depende la explotación (complementariedad)

- La tecnología que puede emplearse en la explotación.

- Las inversiones necesarias, el costo del capital y los plazos de maduración.

- El valor de los bienes o servicios producidos por la explotación, que depende de la demanda" (Strauss,1972: 10-12).

Para determinar el potencial turístico de un territorio existen procedimientos metodológicos muy claros y que, por su versatilidad, en este trabajo fueron utilizados de forma combinada, tal y como se describe a continuación.

\section{REFERENTES METODOLÓGICOS}

Con la finalidad de fundamentar el procedimiento metodológico que permitió determinar el potencial turístico de esta investigación, se hizo una revisión de documentos que han abordado esta temática para conocer de qué forma se ha trabajado. Al examinar 
los contenidos de 325 números publicados por seis revistas² de circulación internacional: cuatro de habla hispana y dos en inglés, pudo detectarse que es mínimo el interés investigativo sobre este enfoque pues sólo el $0.6 \%$ de los artículos desarrollaron metodologías para evaluar los recursos turísticos de los sitios examinados.

Según las temáticas desarrolladas, los 18 artículos identificados, se pudieron agrupar en seis vertientes investigativas: estudios de Áreas Protegidas con la intención de promover un aprovechamiento sustentable de los recursos turísticos naturales existentes en esos espacios (Deng et al., 2002; Dharmaratne et al., 2000;Enríquez et al., 2010; Franco et al., 2009), trabajos que buscan mercados turísticos que desde una perspectiva ambiental puedan promoverse (César y Beltrão, 2012; Constabel y Lizondo, 1999; Honget al., 2003; Melián y García, 2003), documentos que resaltan el potencial turístico que conllevan las expresiones culturales (Salinas y Sulroca, 2010; Rydzik et al., 2013),investigaciones derivadas de una política gubernamental que pretenden fomentar la actividad turística en sus territorios (Kelly,1998; Ramírez y López, 2012), trabajosque ponderan la importancia que tiene esta actividad para las economías a diferentes escalas geográficas (Pratt, 2014; Reis et al., 2012) y artículos que plantean metodologías para determinar la importancia que pueden adquirir nuevos mercados con base en diferentes modalidades turísticas (Couto et al., 2007; Díaz, 2008; Juanet al., 2009; Orgaz y López, 2015; Varjú et al., 2014).

Por otra parte, a principios de los años noventa del siglo pasado, en España, emergió una metodología específica para conocer el potencial turístico de un territorio. Al respecto, Leno (1993) en su tesis de doctorado propuso una vía cualitativa y cuantitativa para valorar los recursos naturales y culturales del Canal de Castilla. Poco tiempo después, este esquema de trabajo lo retomó para elaborar un escrito sobre de técnicas de evaluación del potencial turístico (Leno, 1993a), cuyos procedimientos fundamentaron la investigación de López (1998) en el Alto Palancia (Castellón). La difusión de estas investigaciones a un público científico más diverso ha permitido que otros autores utilicen la metodología para examinar diferentes espacios geográficos, tales son los casos de los parques naturales de la Sierra de Espadán en España y Talassemtane en Marruecos (López et al., 2009), las playas del Departamento del Atlántico en Colombia (Gallardo, 2013), el cantón Pasaje de la provincia de El Oro en Ecuador (Lazo et al., 2017), entre otros.

En este contexto y con el propósito de establecer una representación cartográfica del índice de potencialidad turística que permitiera identificar los contrastes internos de la zona de estudio, se eligió a la tipificación probabilística. Esta vía metodológica fue utilizada por Robert Thürmer (1982) para la regionalización económica; en México, la han utilizado geógrafos en el marco de la Asimilación Económica del Territorio (Propín y Sánchez, 1998; Juárez, 1999; Mendoza, 2001; García Castro, 2007; García Castro, 2011).

2 Según la información disponible, la revisión se hizo para diferentes períodos. En el caso de la revista Estudios y Perspectivas en Turismo, se consultaron los volúmenes publicados entre 1991 - 2015; en el de Gestión Turística, entre 1997 - 2012; en el de Pasos, entre 2003 - 2015; en el de Periplo Sustentable, entre 2007 - 2015; en el de Annals of Tourism Research, entre 1994 - 2015; y en el de International Journal of Tourism Research, entre 2005 - 2015. 
Para esta investigación se tomó la decisión de combinar las metodologías del potencial turístico y la tipificación probabilística (Figura 2); así se fortaleció el tratamiento estadístico, se facilitó el análisis de la información y se obtuvo cartografía que revela patrones territoriales del turismo.

\section{Figura 2}

\section{METODOLOGÍAS CONSIDERADAS EN LA INVESTIGACIÓN}
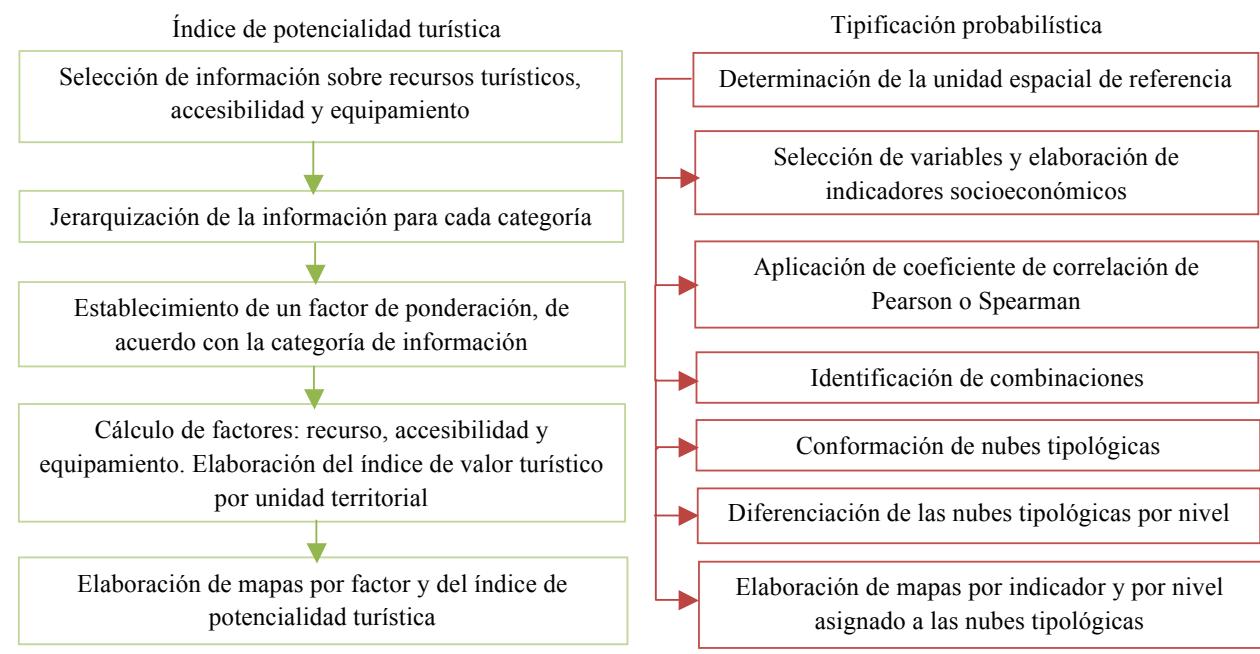

Fuente: Elaboración propia con base en Leno, 1993; López, 1998; Propín y Sánchez, 1998; Juárez, 1999; Mendoza, 2001; García Castro, 2007; García Castro, 2011.

\section{DESARROLLO METODOLÓGICO}

Según la experiencia reportada por quienes han trabajado con el índice de potencialidad turística y el método de tipificación probabilística, existen tres tipos de unidad espacial de referencia (UER): los límites político-administrativos (países, estados, municipios), la cuadrícula geográfica (cuadrados y hexágonos) y las áreas concéntricas (que también pueden ser polígonos irregulares). Para el primer y segundo caso, generalmente se utiliza información proporcionada por instituciones especializadas en la generación de datos físico-geográficos, sociales, económicos y ambientales y se complementa con trabajo de campo; en cambio, cuando se delimita un espacio en función de un punto de interés, predomina la información que recaba de forma directa el investigador.

Al considerar que la zona de estudio abarca 32 municipios distribuidos a lo largo del litoral de los estados de Jalisco, Colima, Michoacán, Guerrero, Oaxaca (Figura 1), se valoró la pertinencia de utilizar una unidad espacial de referencia distinta, que tuviese la virtud de revelar con más detalle la dinámica de la actividad turística. Con este propósito y con base en las coordenadas $15^{\circ} 39^{\prime}$ de latitud Norte y $105^{\circ} 42^{\prime}$ de longitud Oeste (punto de origen) y $20^{\circ} 31^{\prime}$ de latitud Norte y $96^{\circ} 18^{\prime}$ de longitud Oeste(punto opuesto), 
y distancias angulares de cuatro minutos (en dirección vertical y horizontal) se empleó el software Illwis para trazar una malla reticulada integrada por 11.446 cuadrados a los que se les denominó UER (Figura 3).

\section{Figura 3 \\ DIVISIÓN DE LA ZONA DE ESTUDIO CON BASE EN CUADRÍCULA GEOGRÁFICA}

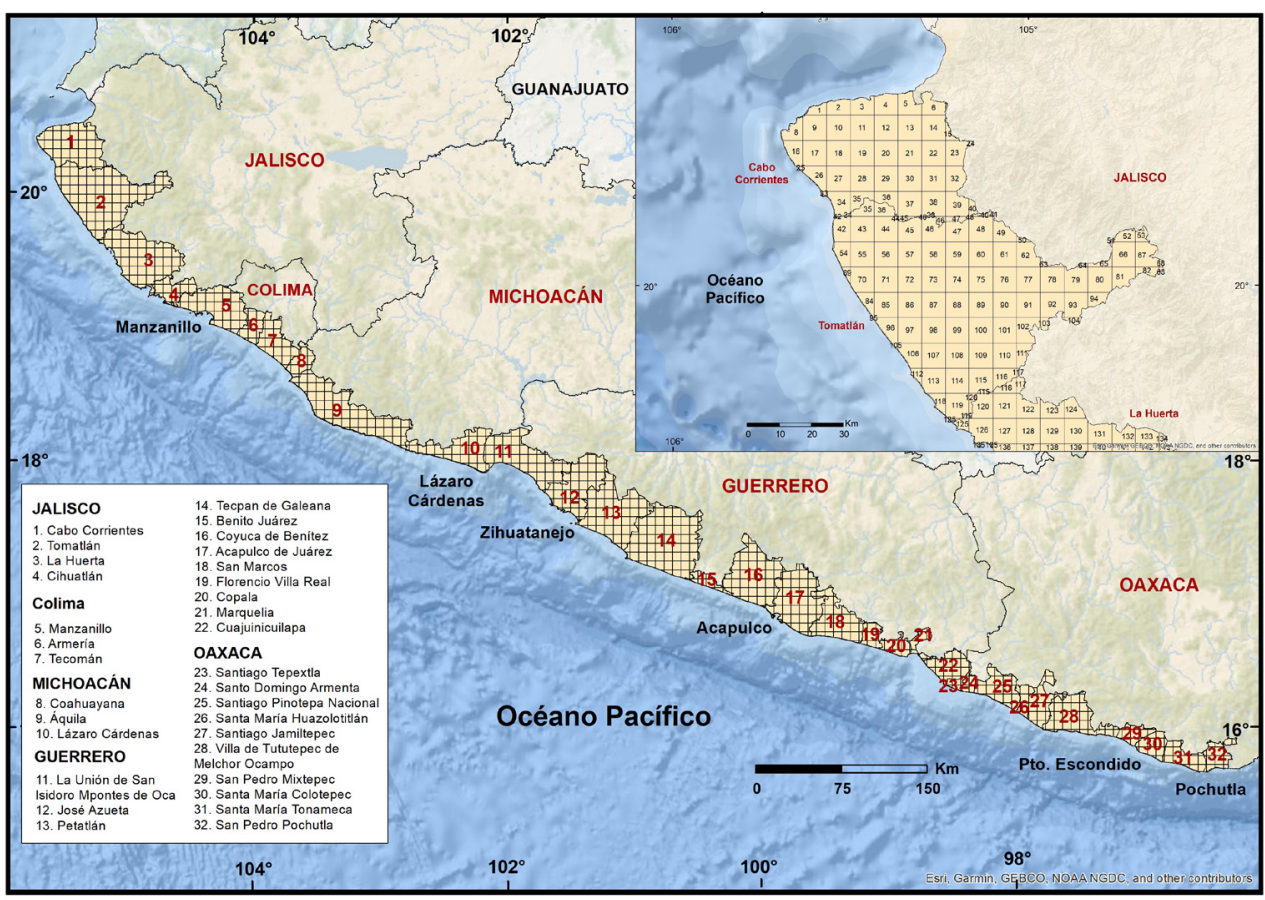

Fuente: Elaboración propia con base en Conabio 2003 y 2010.

Después, la cuadrícula geográfica se exportó en formato shapefile (SHP)para proceder a su intersección con la zona de estudio mediante el uso del software ArcMap ${ }^{3}$. realizar este procedimiento quedaron $901 \mathrm{UER}^{4}$; en otras palabras, sólo se tomaron en cuenta aquellas que quedaron dentro de los límites de los 32 municipios que integran a la región. En una base de datos, para efectos de localización y enumeración, la UER 1 se ubicó en el municipio de Cabo Corrientes del estado de Jalisco; de forma secuencial, de izquierda a derecha y de forma descendente se asignó un número a las otras 900 de tal manera que la UER 901 se halla en el municipio San Pedro Pochutla en el estado de Oaxaca (Figura 3).

3 Aunque ArcMap cuenta con herramientas que permiten trazar de forma directa la cuadrícula, para este trabajo, con la intención de un mayor control de las características de la retícula, se utilizaron los dos software.

4 El área promedio de las UER completas fue de a $51.5 \mathrm{~km}^{2}$ (481 UER); las demás, situadas en la periferia, tuvieron superficies menores. 
Lo siguiente fue seleccionar las variables que permitieran evaluar la dinámica de la actividad turística en la zona de estudio. Al respecto, si bien Leno (1993), López (1998) y otros investigadores dan indicios de los elementos a considerar y cómo conseguir los datos, para este trabajo se hicieron los siguientes ajustes:

- En principio se tomaron en cuenta los elementos que conforman la oferta básica, los recursos turísticos naturales y culturales. Para tal fin se consideró que la vegetación, las formas del relieve, las corrientes y los cuerpos de agua, así como las distintas manifestaciones culturales tangibles e intangibles, constituyen las unidades paisajísticas que atraen el interés de los turistas; de forma adicional, se identificaron aquellos elementos naturales que ya tienen un aprovechamiento económico relativo con actividades de ocio y recreación (Cuadro 1).

\section{Cuadro 1 \\ VARIABLES SELECCIONADAS PARA DETERMINACIÓN DE FACTORES DE POTENCIALIDAD TURÍSTICA}

\begin{tabular}{llc}
\hline \multicolumn{1}{c}{ Variables } & \multicolumn{1}{c}{ Fuente de información } & Factor \\
\hline Vegetación & $\begin{array}{l}\text { Cartografía en formato shp del Instituto Nacional } \\
\text { de Estadística y Geografía (INEGI, 2019a) y de la }\end{array}$ & Recurso \\
Topoformas & $\begin{array}{l}\text { Comisión nacional para el conocimiento y uso de } \\
\text { la biodiversidad (CONABIO, 2019); además de }\end{array}$ & \\
Hidrografía & sitios de internet, Google Earth y trabajo de campo. & \\
Atractivos turísticos naturales & & \\
Recursos turísticos culturales & & \\
Alojamiento & $\begin{array}{l}\text { Directorio Estadístico Nacional de Unidades } \\
\text { Económicas (DENUE) del Instituto Nacional de }\end{array}$ & \\
Alimentos y bebidas & Estadística y Geografía (INEGI, 2019), sitios de & \\
Servicios turísticos & internet y trabajo de campo. & \\
Carreteras & Cartografía en formato shp de INEGI (2019a) y & Accesibilidad \\
Gasolineras & CONABIO (2019), datos del DENUE (INEGI, & \\
Centrales de autobuses & 2019) y Google Earth. & \\
\hline
\end{tabular}

Fuente: Elaboración propia.

Es importante mencionar que, debido al actual contexto social de México en materia de violencia e inseguridad, para esta investigación ${ }^{5}$ se consideró la incidencia delictiva

5 En el último recorrido realizado en la zona de estudio para la identificación de nuevos destinos turísticos, en la ciudad de Lázaro Cárdenas, una persona advirtió al responsable del equipo de trabajo que habían sido monitoreados desde Jalisco; para constatar sus dichos, dio información general de cada integrante y de los sitios en donde habían estado recabando información; después proporcionó indicaciones específicas de los tramos de carretera que debían seguirse y en caso de ser detenidos, dar ciertos nombres para poder continuar con el viaje y salir del estado de Michoacán. 
como variable condicionante para el éxito de los destinos turísticos y no un componente en el cálculo de su índice de potencialidad.

- En segundo lugar, se eligieron las variables asociadas con la oferta turística complementaria que ofrecen los centros de ocio y recreación, en este caso se incluyeron los distintos tipos de alojamiento, los establecimientos de alimentos y bebidas, así como los centros de servicios turísticos (Cuadro 1).

- Luego, una tercera etapa en el procedimiento consistió en evaluar la accesibilidad que posee la región para que los turistas se desplacen por tierra hacia a los diferentes sitios turísticos. En este caso se obtuvieron datos sobre la longitud y condición de la red carretera, tanto de terracería como pavimentada, de igual forma se agregó información sobre gasolineras y centrales de autobuses (Cuadro 1).

Una vez identificadas las variables para cada uno de los factores que conforman el índice de potencialidad turística, el siguiente paso fue jerarquizar en cinco categorías cada conjunto de datos y analizarlos con base en valores de ponderación, según se detalla a continuación.

En el caso de los recursos turísticos que conforman la oferta básica, se tomó en cuenta el método de jerarquización de la Organización de los Estados Americanos (OEA), modificado por Álvarez (1987, p. 78). Es necesario puntualizar que, si bien para cada componente se utilizan criterios distintos según su propia naturaleza, es importante tomar como base la diferenciación de cada elemento que hace la OEA a partir de su posible relevancia para el desarrollo turístico del lugar. En consecuencia, se utilizaron cinco jerarquías:

5: interés internacional

3: interés regional

1: recursos con poco o nulo interés
4: interés nacional

2: interés local

Además, debido a que existen territorios en donde algunos de los elementos que se examinan están ausentes, se introdujo la "Jerarquía 0: nulo o sin presencia del elemento". Así, en este trabajo con base en estas seis categorías, a cada unidad integradora de las variables seleccionadas: vegetación, formas del relieve, hidrografía, elementos de la naturaleza que ya tienen un uso turístico y las expresiones culturales, se les diferenció cualitativamente. Lo anterior se observa en el Cuadro 2.

También fue importante valorar qué tipo de infraestructura y servicios turísticos son relevantes para el desarrollo de la actividad turística; por ello, con fines prácticos se examinaron aquellos elementos que pudieron ser ubicados geográficamente. Por lo tanto, en primer lugar, se encuentran a los sitios que brindan hospedaje a los turistas, después, los establecimientos de alimentos y bebidas y, por último, los lugares que permiten el traslado, la comunicación y las transacciones económicas para cubrir los gastos que realizan dichos viajeros durante su estancia en los centros de ocio y recreación. Las categorías asignadas para cada grupo de variables se establecieron con base en valoraciones cualitativas de las unidades económicas y, por el tipo de servicio que proporcionan (Cuadro 3). 
Para examinar la accesibilidad, de acuerdo con la información recabada, fue necesario introducir ponderaciones cuantitativas y cualitativas (Cuadros 4 y 5). La determinación de los intervalos de las clases que permitieron definir las jerarquías para cada variable se hizo con base en el método que proporcionó una mejor distribución de los datos (Gómez, 2004).

Una vez que los distintos componentes de una variable han sido diferenciados por categoría jerárquica, es fundamental establecer los factores de ponderación que asignan a su vez la relevancia que cada variable dentro del conjunto tiene para el desarrollo de la actividad turística. Al respecto, Leno (1993) propone que los valores sean dados en décimas para que en total sumen la unidad; además, plantea que de forma inherente todo elemento tiene relevancia en función de su naturaleza e importancia, por ello sugiere que debe sumársele una constante $\mathrm{K}=1$ (Cuadro 6). Así, con base en las categorías y coeficientes de ponderación, los Cuadros 6 a 8 muestran los procedimientos metodológicos que se establecieron para calcular los indicadores que integran los factores que se requieren para determinar los índices de potencialidad turística.

Como puede deducirse del Cuadro 6, se obtuvieron seis indicadores para cada una de las 901 UER. Estos valores a través de la fórmula: FR = VV + VTP + VCA + VRP + VATN + VRTC, conforman el índice del Factor Recurso (FR).

Al aplicar esta fórmula se obtuvo el índice del FR para las 901 UER que integran la región. Ahora bien, con la finalidad de detectar si, desde un punto de vista espacial, estos datos presentaban patrones en su distribución territorial según su índice de concentración de riqueza natural y cultural para el desarrollo de la actividad turística, fueron agrupados en cinco categorías: Muy Alto (5), Alto (4), Medio (3), Bajo (2) y Muy Bajo (1); así, con base en la teoría del color: tonalidades frías para valores bajos y cálidas para valores altos, se obtuvo un mapa de fondo cualitativo (Figura 4).

\section{Cuadro 2}

\section{JERARQUIZACIÓN DE LAS VARIABLES DEL FACTOR RECURSOS}

\begin{tabular}{cl}
\hline Jerarquía & \multicolumn{1}{c}{ Variables / componentes } \\
\hline & \multicolumn{1}{c}{ VEGETACIÓN } \\
\cline { 2 - 2 } 1 & Sin elemento \\
2 & $\begin{array}{l}\text { Manglar, vegetación de galería, bosque de galería, selva de galería, popal, tular, } \\
\text { pastizal natural, sabanoide, Pastizal halófilo, vegetación halófila hidrófila, vegetación } \\
\text { halófila xerófila }\end{array}$ \\
& $\begin{array}{l}\text { Selva mediana subcaducifolia, selva baja subcaducifolia, bosque de encino, bosque } \\
\text { mesófilo de montaña. }\end{array}$ \\
& Selva mediana caducifolia, selva baja caducifolia, bosque de pino. \\
5 & Selva mediana subperennifolia, bosque de encino-pino, bosque de pino-encino
\end{tabular}




\begin{tabular}{|c|c|c|}
\hline Jerarquía & \multicolumn{2}{|c|}{ Variables / componentes } \\
\hline & \multicolumn{2}{|c|}{ TOPOFORMAS } \\
\hline 0 & \multicolumn{2}{|l|}{ Sin elemento ${ }^{6}$} \\
\hline 1 & \multicolumn{2}{|c|}{$\begin{array}{l}\text { Llanura costera, llanura con lomerío, llanura costera con lomerío, llanura costera con } \\
\text { lomerío de piso rocoso o cementado, llanura costera de piso rocoso o cementado, } \\
\text { llanura costera salina, lomerío con llanuras, lomerío típico }\end{array}$} \\
\hline 2 & \multicolumn{2}{|c|}{$\begin{array}{l}\text { Cañóntípico, sierra alta completa, sierra baja, sierra baja completa, sierra de cumbres } \\
\text { tendidas, valle de laderas escarpadas, valle de laderas tendidas, valle de laderas } \\
\text { tendidas con lomeríos, valle intermontano, valle intermontano con lomerío, Valle } \\
\text { ramificado, Valle ramificado con lomerío }\end{array}$} \\
\hline 3 & \multicolumn{2}{|c|}{$\begin{array}{l}\text { Llanura costeracon deltas, llanura costera con deltas de piso rocoso o cementado, } \\
\text { llanura costera con deltas inundables y salina. }\end{array}$} \\
\hline 4 & \multicolumn{2}{|c|}{$\begin{array}{l}\text { Llanura costera con lagunas costeras, llanura costera con lagunas costeras de piso } \\
\text { rocoso o cementado, llanura costera con lagunas costeras salina, llanura costera } \\
\text { inundable con lagunas costeras. }\end{array}$} \\
\hline \multirow[t]{4}{*}{5} & \multicolumn{2}{|c|}{ Playa o llanura inundable y salina, Playa o barra salina } \\
\hline & \multicolumn{2}{|c|}{ HIDROGRAFÍA } \\
\hline & Ríos perennes & $\begin{array}{l}\text { Cuerpos de agua marítimos, } \\
\text { intermitentes y perennes }\end{array}$ \\
\hline & Longitud $(\mathrm{Km})$ & Superficie $\left(\mathrm{km}^{2}\right)$ \\
\hline 0 & 0 & 0 \\
\hline 1 & $9^{-4}-0.98$ & $<0.9$ \\
\hline 2 & $1.0-5.9$ & $1.0-5.8$ \\
\hline 3 & $6.0-10.9$ & $6.1-8.1$ \\
\hline 4 & $11.1-15.8$ & $10.3-14.8$ \\
\hline 5 & $16.2-21.8$ & $18.5-23.7$ \\
\hline
\end{tabular}

ATRACTIVOS TURÍSTICOS NATURALES Y CULTURALES

Naturales Culturales

$\begin{array}{lll}0 & \text { Sin elemento } & \text { Sin elemento } \\ 1 & \text { Cerros } & \text { Sitios arqueológicos } \\ 2 & \text { Islas, parques } & \text { Edificios } \\ 3 & \text { Ríos, arroyos, manantiales } & \text { Museos y artesanías } \\ 4 & \text { Lagunas, esteros } & \text { Edificios históricos, iglesias } \\ 5 & \text { Playas } & \text { Gastronomía, fiestas }\end{array}$

Fuente: Elaboración propia.

6 Para fines prácticos de comparación con los otros cuadros, en éste se dejaron las 6 categorías, aunque, la 0 no procede pues se reconoce que todo territorio tiene una expresión geomorfológica 


\section{Cuadro 3 \\ JERARQUIZACIÓN DE LAS VARIABLES DEL FACTOR EQUIPAMIENTO}

\begin{tabular}{|c|c|c|c|}
\hline \multirow[t]{2}{*}{ Jerarquía } & \multicolumn{3}{|c|}{ Elementos } \\
\hline & Hoteles y servicios integrados & Restaurantes & Otros servicios \\
\hline 0 & 0 & 0 & 0 \\
\hline 1 & $\begin{array}{l}\text { Pensiones, departamentos y } \\
\text { casas }\end{array}$ & $\begin{array}{l}\text { Otros restaurantes con servicio } \\
\text { limitado }\end{array}$ & - \\
\hline 2 & Moteles & $\begin{array}{l}\text { Restaurantes de autoservicio / } \\
\text { comida para llevar }\end{array}$ & - \\
\hline 3 & Cabañas, villas y similares & Bares, cantinas y similares & $\begin{array}{l}\text { Casas de cambio y } \\
\text { bancos }\end{array}$ \\
\hline 4 & Hoteles sin otros servicios & $\begin{array}{l}\text { Restaurantes sin servicio } \\
\text { completo }\end{array}$ & Cibercafés \\
\hline 5 & Hoteles con otros servicios & $\begin{array}{l}\text { Restaurantes con servicio } \\
\text { completo }\end{array}$ & Agencias de viajes \\
\hline
\end{tabular}

Fuente: elaboración propia.

\section{Cuadro 4}

JERARQUIZACIÓN DE VARIABLE DEL FACTOR ACCESIBILIDAD (CARRETERAS)

\begin{tabular}{cccccccc}
\hline Jerarquía & Densidad & \multicolumn{9}{c}{ Pavimentada } \\
& & \multicolumn{2}{c}{ Cuota } & \multicolumn{2}{c}{ Libre } \\
& $\mathrm{Km} / \mathrm{km}^{2}$ & 4 carriles & 4 carriles & 2 carriles & Construcción & 2 carriles & Restringida \\
\hline 0 & 0 & 0 & 0 & 0 & 0 & 0 & 0 \\
1 & $3^{-4}-9^{-3}$ & $0.49-0.93$ & $0.54-0.84$ & $5^{-3}-0.90$ & 0.25 & $0.01-0.93$ & $0.01-0.97$ \\
2 & $0.01-0.05$ & $1.31-3.48$ & $1.28-2.47$ & $1.02-2.99$ & 1.47 & $1.00-2.94$ & $1.18-1.79$ \\
3 & $0.06-0.25$ & $4.12-6.82$ & $3.17-3.77$ & $3.03-9.96$ & 3.01 & $3.06-9-90$ & $2.01-5.54$ \\
4 & $0.26-0.86$ & $7.07-8.28$ & 7.47 & $10.09-13.90$ & - & $10.08-12.25$ & $6.38-8.84$ \\
5 & $0.94-1.49$ & $9.06-11.47$ & $10.21-10.51$ & $14.39-18.96$ & 9.11 & $13.39-16.47$ & $9.03-11.04$ \\
\hline
\end{tabular}

Fuente: Elaboración propia

\section{Cuadro 5 \\ JERARQUIZACIÓN DE VARIABLES DEL FACTOR ACCESIBILIDAD (GASOLINERAS Y CENTRALES DE AUTOBUSES)}

\begin{tabular}{ccc}
\hline Jerarquía & Elementos \\
& Gasolineras & Centrales de autobuses \\
\hline 0 & 0 & 0 \\
1 & 1 & $1-2$ \\
2 & 2 & $3-4$ \\
3 & 3 & $6-8$ \\
4 & 4 & $11-13$ \\
5 & - & 17 \\
\hline
\end{tabular}

Fuente: Elaboración propia. 


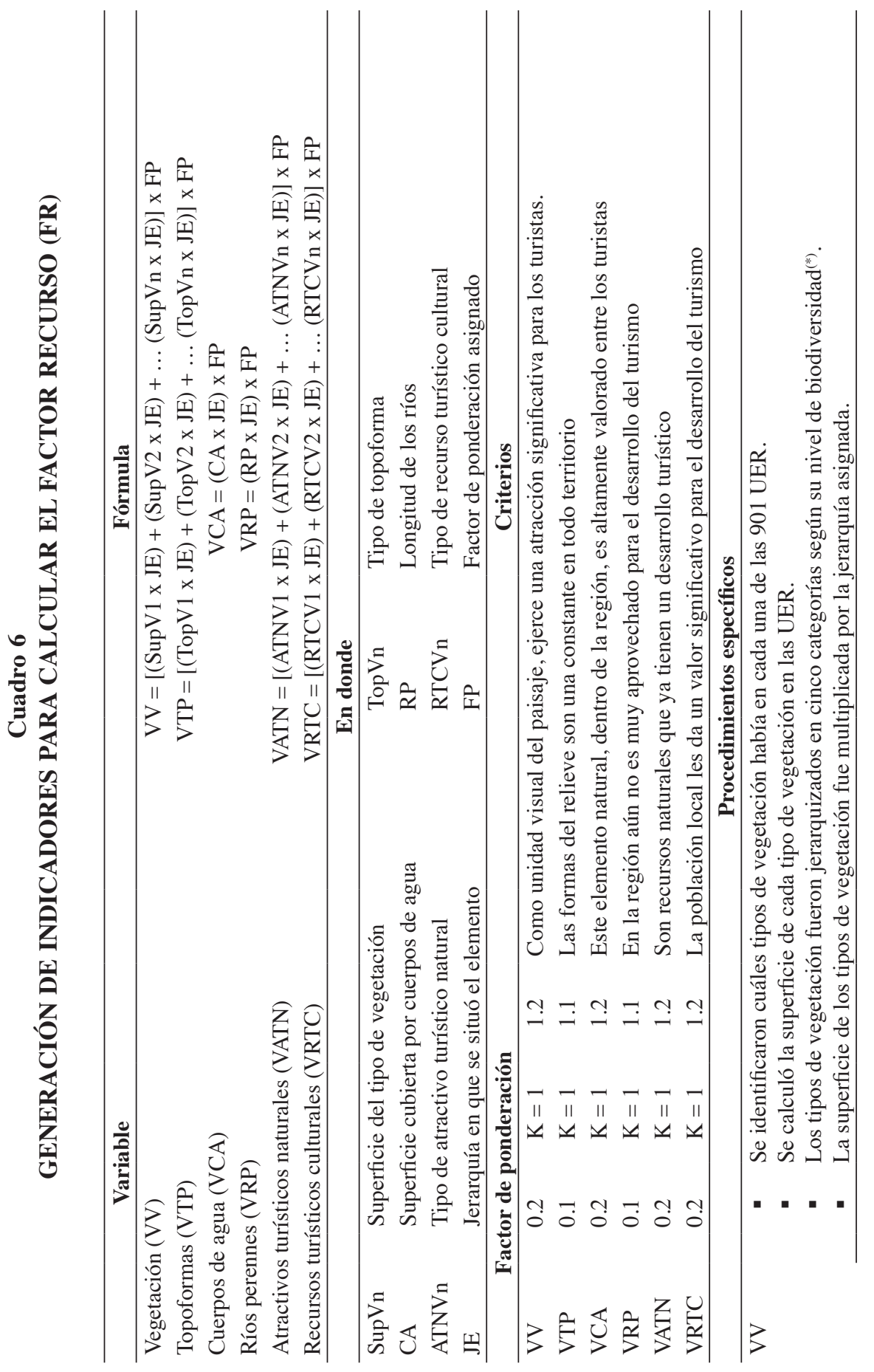




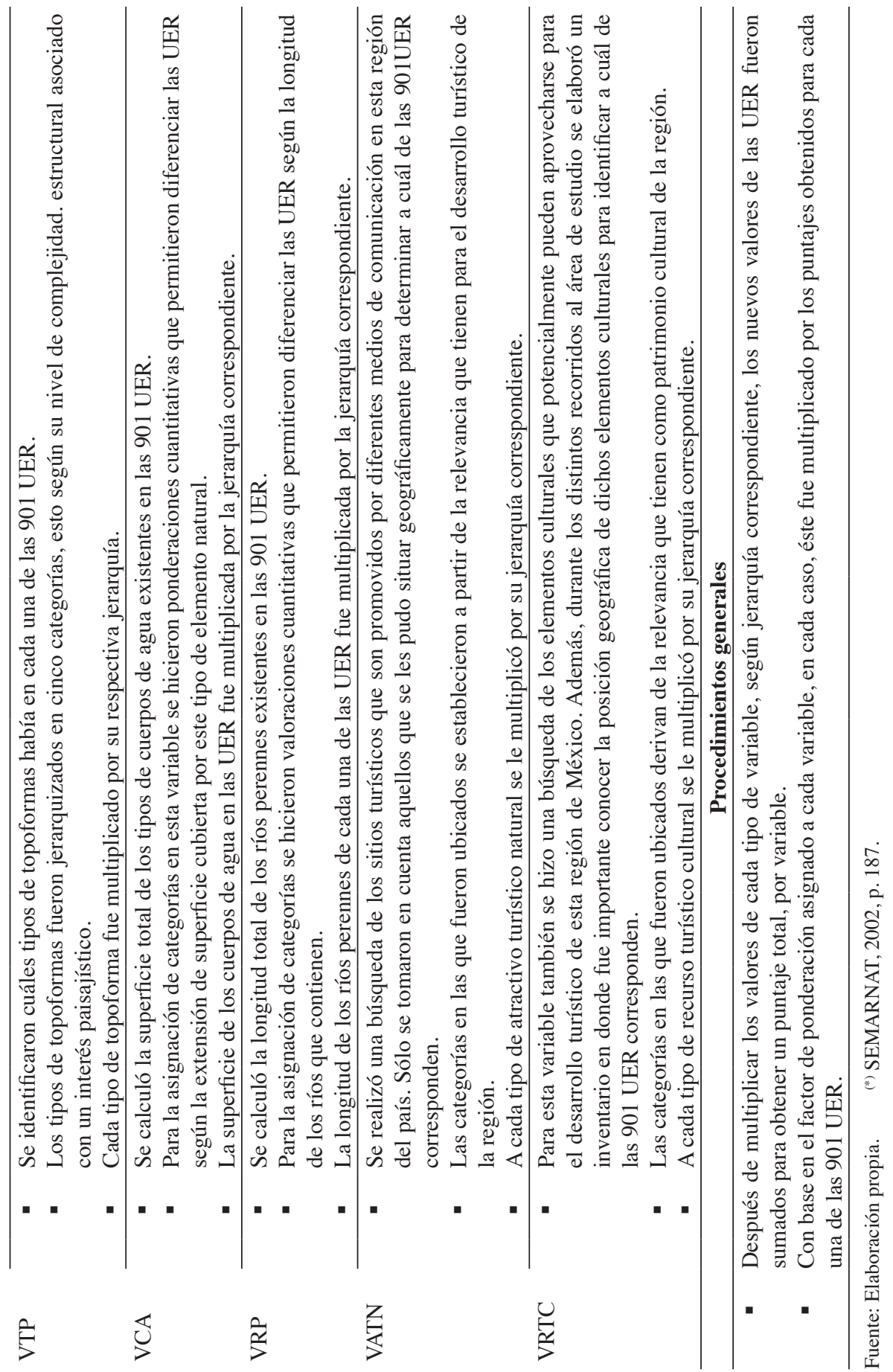




\section{Figura 4 \\ DINÁMICA DE LA ACTIVIDAD TURÍSTICA: FACTOR RECURSO}

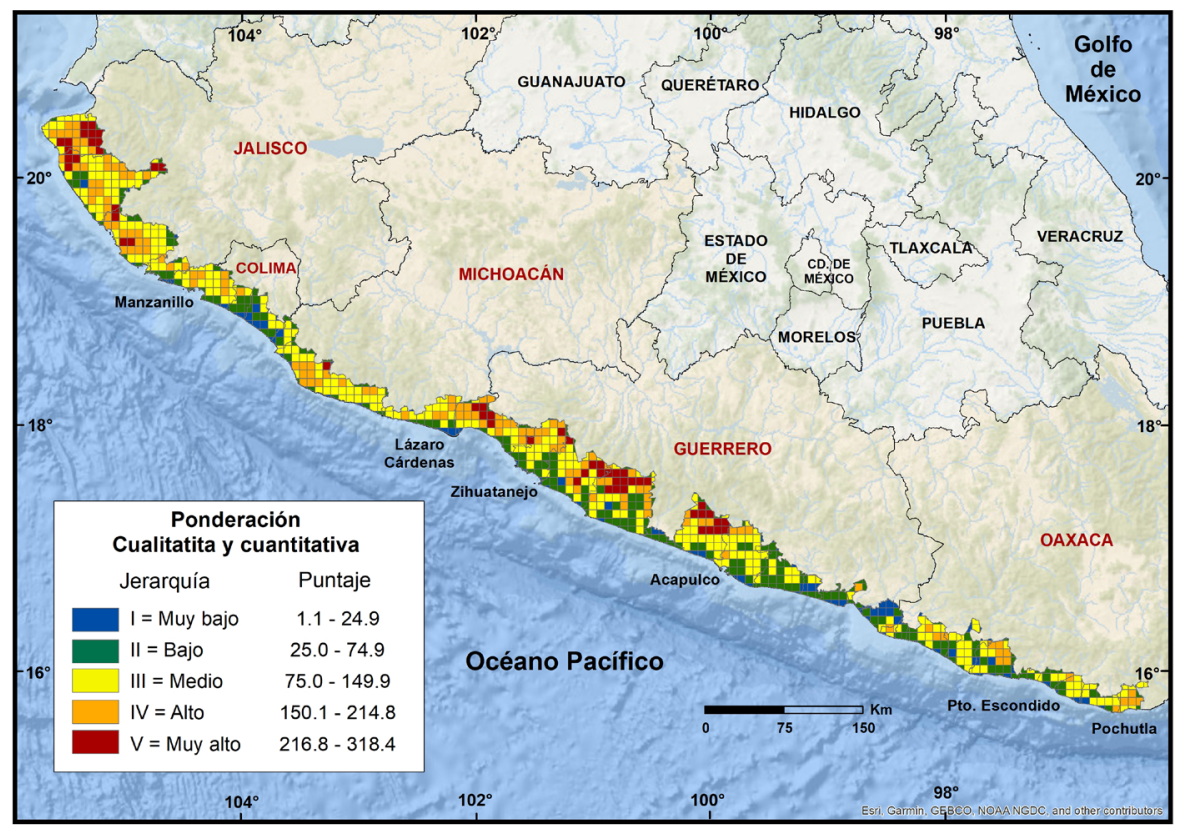

Fuente: Elaborado con base en Cuadros 2 y 6; Figura 3.

Las valoraciones cualitativas y cuantitativas hechas sobre la oferta básica de la zona de estudio revelaron que 55 UER (8.5\% del territorio)tienen niveles Muy Altos de elementos naturales o culturales, en 133 UER (20\%) su índice es Alto, en 295 UER (41\%) es Medio, en 235 UER (24\%) es Bajo y en 183 UER (6\%) es Muy Bajo. Por otra parte, al examinar los patrones territoriales de esta diversidad asociada con el fenómeno turístico, se encontró que los índices más altos se concentran en mayor grado en las zonas montañosas de los estados de Jalisco y Guerrero. Este hecho llamó la atención toda vez que los escenarios de playa y mar atraen casi de forma exclusiva el interés de los visitantes; lo que implicó que a través de estos procedimientos se detectaron lugares que potencialmente pueden sumarse a la dinámica turística de la región.

En cuanto al Factor Equipamiento, su índice fue calculado a través de tres variables (Cuadro 7). Aquí cabe resaltar que la oferta complementaria constituye el eje rector que permite la consolidación de un mercado turístico; sin embargo, por lo general tiende a generar desequilibrios regionales al hallarse polarizada en aquellos sitios en donde las iniciativas públicas y privadas consideran que puede darse una amortización rápida del capital invertido.

Tal y como lo establece el Cuadro 7, estas consideraciones metodológicas permitieron ponderar la oferta complementaria que ha sido construida o habilitada para el turismo en la región. Así se obtuvieron los indicadores que conforman el Factor Equipamiento (FE), cuya fórmula fue: $\mathrm{FE}=\mathrm{VH}+\mathrm{VAB}+\mathrm{VST}$. 


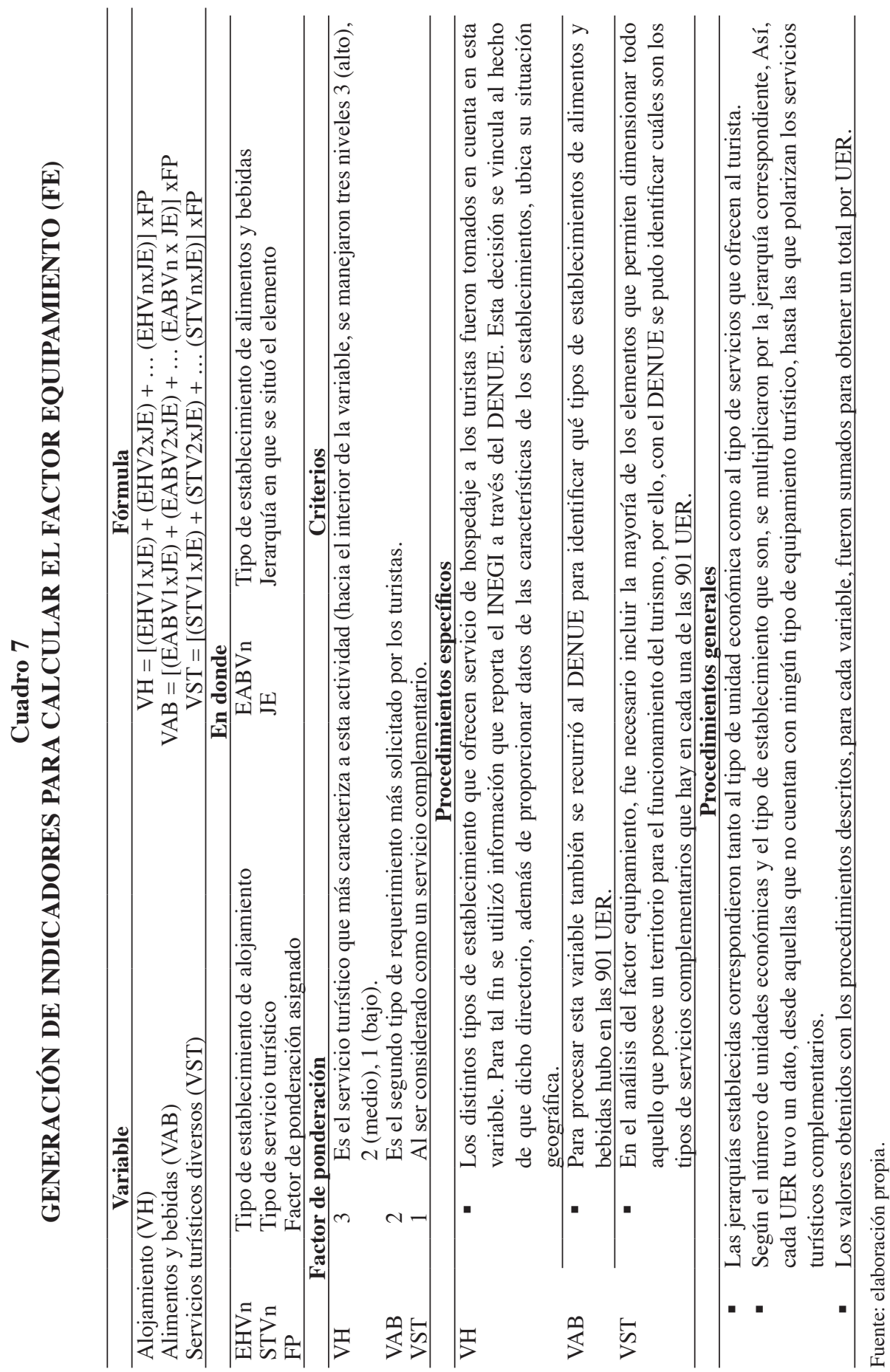


Por otra parte, al elaborar el mapa correspondiente (Figura 5), la expresión territorial de este índice hizo evidente que la cobertura de equipamiento en la costa del Pacífico Suroccidental de México es escasa. En este sentido, los niveles Muy alto y Alto, en conjunto suman tan sólo 13 UER, mismas que corresponden con los principales centros turísticos: Manzanillo, Lázaro Cárdenas, Zihuatanejo, Acapulco, Puerto Escondido y Pochutla, entre otros.

\section{Figura 5
DINÁMICA DE LA ACTIVIDAD TURÍSTICA: FACTOR EQUIPAMIENTO}

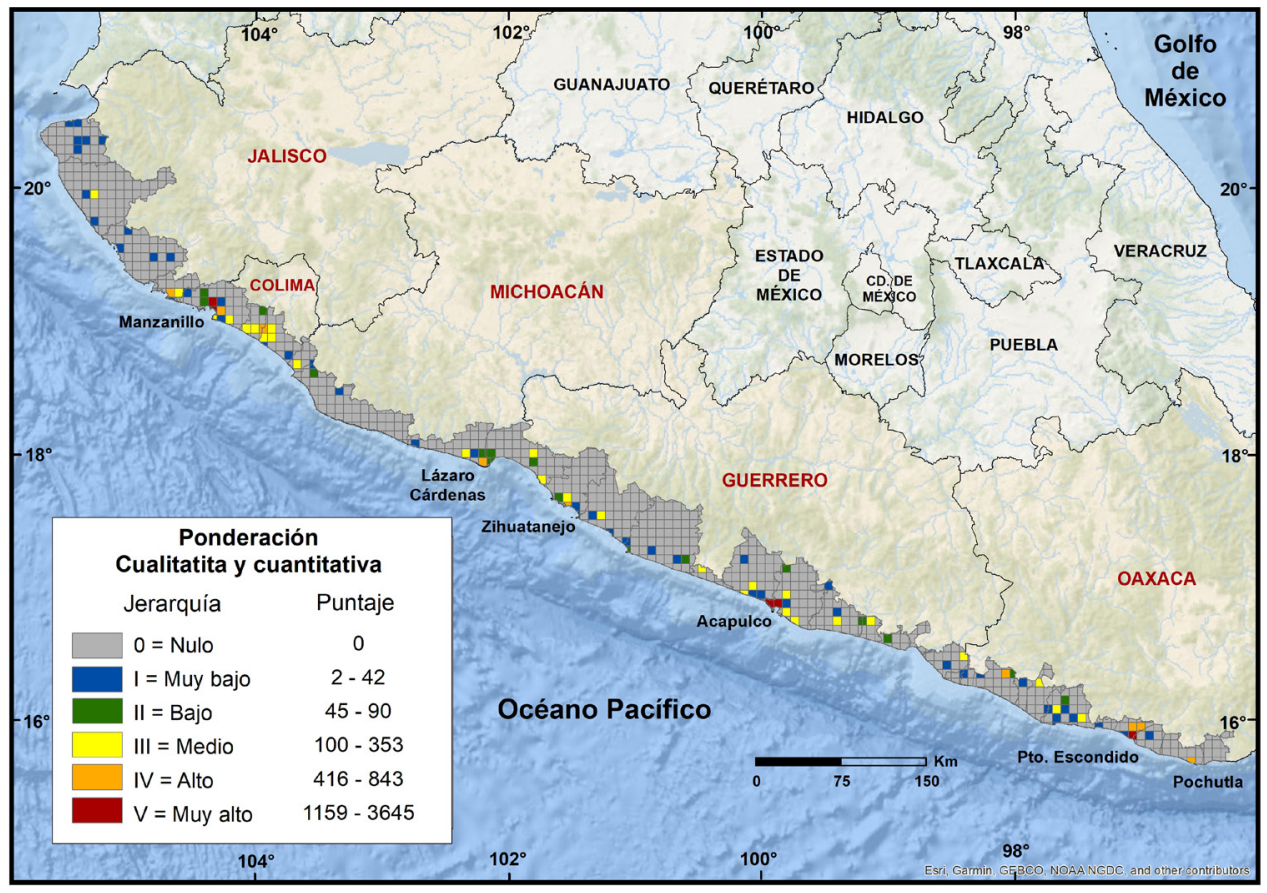

Fuente: Elaborado con base en Cuadros 3 y 7; Figura 3.

Como parte del análisis espacial de las actividades turísticas debe considerarse el grado de accesibilidad del lugar donde se sitúan. Este punto es necesario porque tanto en términos de accesibilidad física como de accesibilidad del mercado, la proximidad a los centros emisores de la demanda cobra relevancia (Leno,1993: 837). De hecho, no se debe perder de vista que esta particularidad de un territorio determinará de un modo casi absoluto el volumen de visitantes a un centro turístico; en otras palabras, la demanda es muy sensible a un incremento en el coste económico o de tiempo de viaje en su experiencia turística, por lo cual optará por aquel atractivo o centro turístico que sea más accesible.

En este contexto, según Leno (1993: 837) la accesibilidad constituye generalmente un factor crítico en cualquier proceso de evaluación del potencial turístico de una zona o 
región a desarrollar. Su tratamiento en el proceso de evaluación depende estrechamente de los objetivos que se persigan con la planificación, del tipo de actividades que se programen y de las características de la demanda a la que va dirigido el proyecto turístico.

Para este trabajo, se calculó el Factor de Accesibilidad (FA) por medio de cuatro indicadores. En este sentido, el Cuadro 8 sintetiza los procedimientos metodológicos más importes. La fórmula utilizada para determinar este índice fue: $\mathrm{FA}=(\mathrm{VDV} \mathrm{VPP})+$ $(\mathrm{VCCxVP})+(\mathrm{VGxVP})+(\mathrm{VCA} x \mathrm{VP})$

La Figura 6 muestra la manifestación espacial de este componente del índice de potencialidad turística. Las particularidades territoriales más significativas son: 16 UER detentan las dos jerarquías de mayor nivel; estos cuadrantes están situadas en los municipios de Manzanillo, Tecomán, Lázaro Cárdenas, La Unión, José Azueta, Petatlán, Tecpan de Galeana, Acapulco de Juárez, Santiago Pinotepa Nacional, San Pedro Mixtepec y Santa María Colotepec, los que, a su vez, contienen los principales centros urbanos y destinos turísticos más consolidados de la región.

La jerarquía de nivel medio caracteriza a territorios en torno a las UER del grupo anterior; pero también son propias de los cuadrantes por donde cruzan los ejes carreteros que comunican a esta región con otras áreas del interior del país. Por otra parte, esta porción del territorio nacional muestra amplias zonas que están incomunicadas, varias de ellas, con diversos recursos naturales y culturales con vocación turística.

Dentro de la metodología desarrollada por Leno (1993) y utilizada por López (1998), Gallardo (2013) y otros autores, la cartografía para representar el índice de potencialidad turística es limitada en cuanto a la diferenciación de los contrastes territoriales que conlleva la concentración de los elementos evaluados. Por ello, en este trabajo se recurrió a algunos procedimientos de la tipificación probabilística tales como la identificación de combinaciones según las variables examinadas, la elaboración de nubes tipológicas y la elaboración de un mapa de fondo cualitativo.

En relación con lo anterior, al determinar los tres factores del índice de potencialidad turística, fue necesario integrarlos en un solo indicador, para tal fin, los tres valores obtenidos para cada una de las 901 UER fueron asociadas como combinaciones. A manera de ejemplo, en el Cuadro 9 se presentan cuatro asociaciones diferentes. 


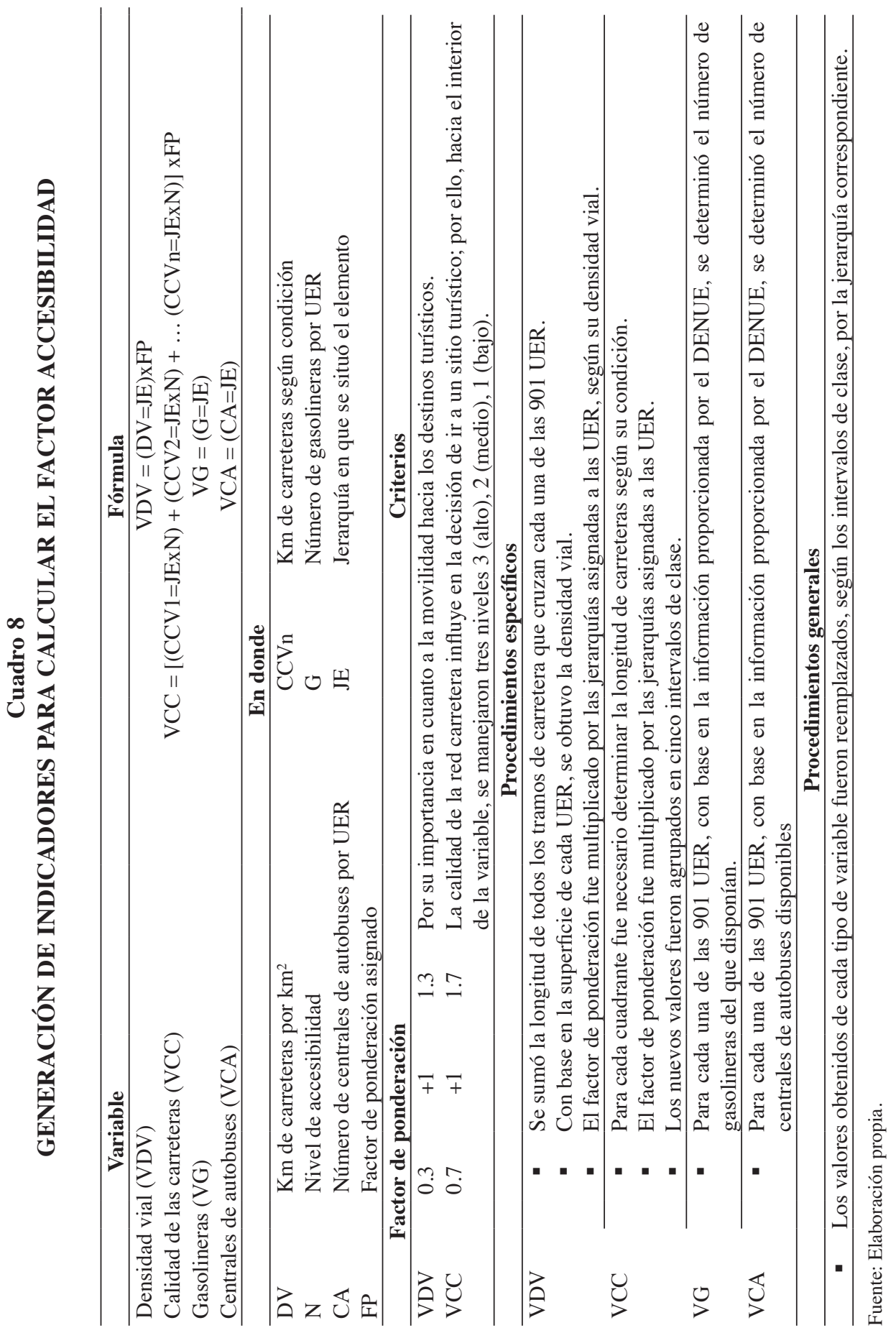




\section{Figura 6 \\ DINÁMICA DE LA ACTIVIDAD TURÍSTICA: FACTOR ACCESIBILIDAD (FA)}

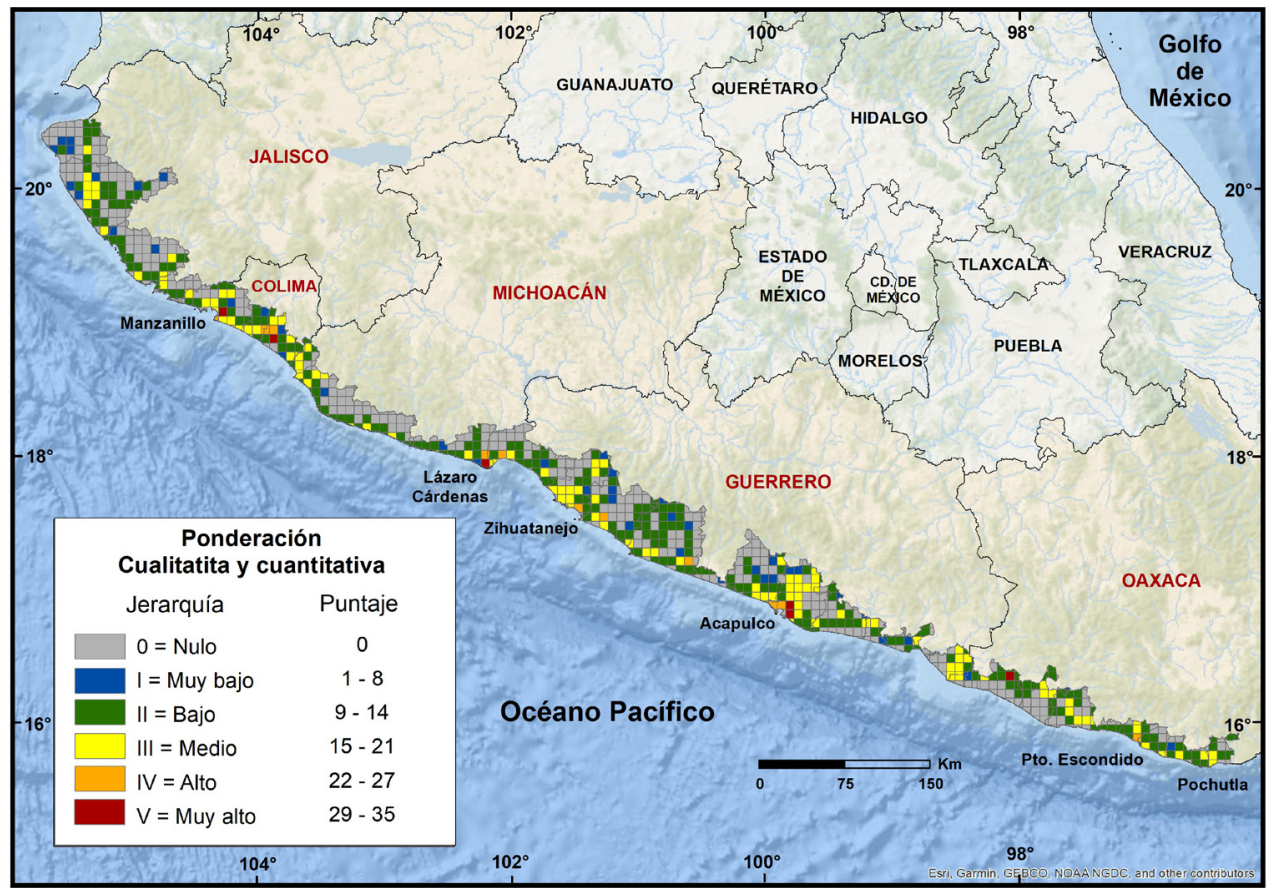

Fuente: Elaborado con base en Cuadros 4, 5 y 8; Figura 3.

\section{Cuadro 9}

EJEMPLOS DE COMBINACIONES DE LOS FACTORES QUE INTEGRAN EL ÍNDICE DE POTENCIALIDAD TURÍSTICA

\begin{tabular}{ccccc}
\hline Número de UER & Factor recurso & $\begin{array}{c}\text { Factor } \\
\text { equipamiento }\end{array}$ & $\begin{array}{c}\text { Factor } \\
\text { accesibilidad }\end{array}$ & Combinación \\
\hline 5 & 3 & 0 & 2 & 302 \\
125 & 2 & 0 & 2 & 202 \\
408 & 4 & 2 & 2 & 422 \\
784 & 2 & 3 & 3 & 233 \\
\hline
\end{tabular}

Fuente: Elaboración propia.

De lo anterior puede deducirse que en total se obtuvieron 901 combinaciones que evidencian la dinámica turística que se presenta en la región costera Sur occidental del Pacífico Mexicano. Por lo cual fue necesario emplear un último procedimiento para identificar las tendencias territoriales de esta actividad económica. 
Como parte de la tipificación probabilística se requiere agrupar las combinaciones obtenidas en nubes tipológicas (Cuadro 10), pues éstas permiten la asociación de diferentes indicadores, lo que facilita a su vez, elaborar una representación cartográfica sintética que muestre los contrastes interno-regionales en torno a temas geográficos diversos.

Así, una vez obtenidas todas las combinaciones posibles para la zona de estudio, se determinó su frecuencia y se identificó las UER que tienen la misma combinación. Con esta información se procedió a elaborar las nubes tipológicas, las cuales se caracterizan por tener un centro que coincide con la combinación de mayor repetitividad o en torno a la cual confluyan las combinaciones más afines a ella (Cuadro 10). A través de este método se determinó que la región costera Sur occidental del Pacífico Mexicano posee trece niveles de potencialidad turística (Figura 7). Para su representación cartográfica se empleó el método de fondo cualitativo.

\section{Cuadro 10 \\ EJEMPLOS DE CONFORMACIÓN DE NUBES TIPOLÓGICAS}

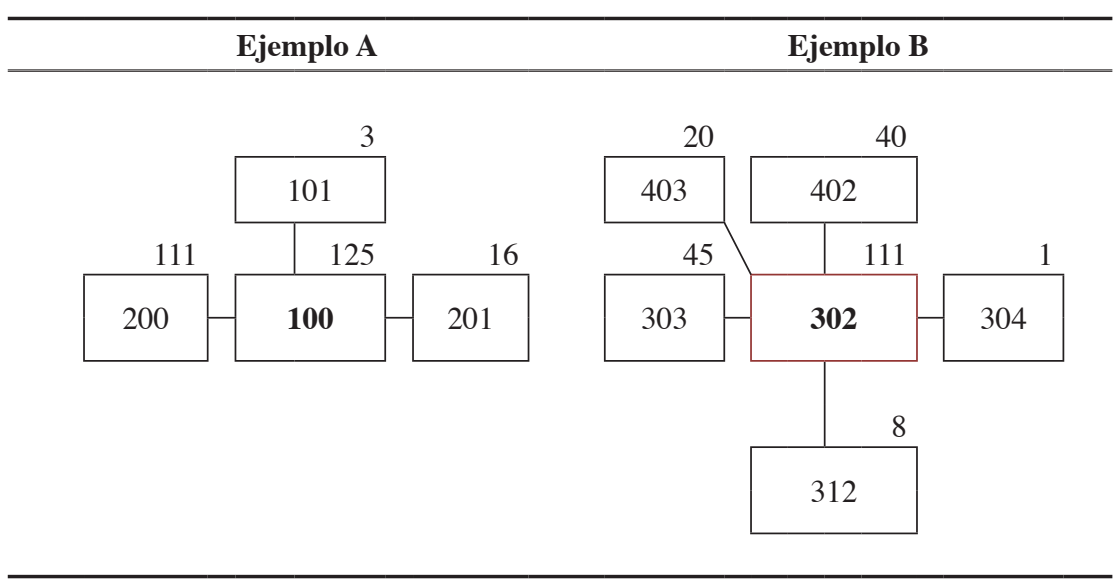

Nota: las combinaciones 100 y 302 representan el centro de nube para cada caso Fuente: Elaboración propia. 


\section{Figura 7 \\ DISTRIBUCIÓN TERRITORIAL DE LOS NIVELES DE POTENCIALIDAD TURÍSTICA DE LA REGIÓN COSTERA SUR OCCIDENTAL DEL PACÍFICO MEXICANO}

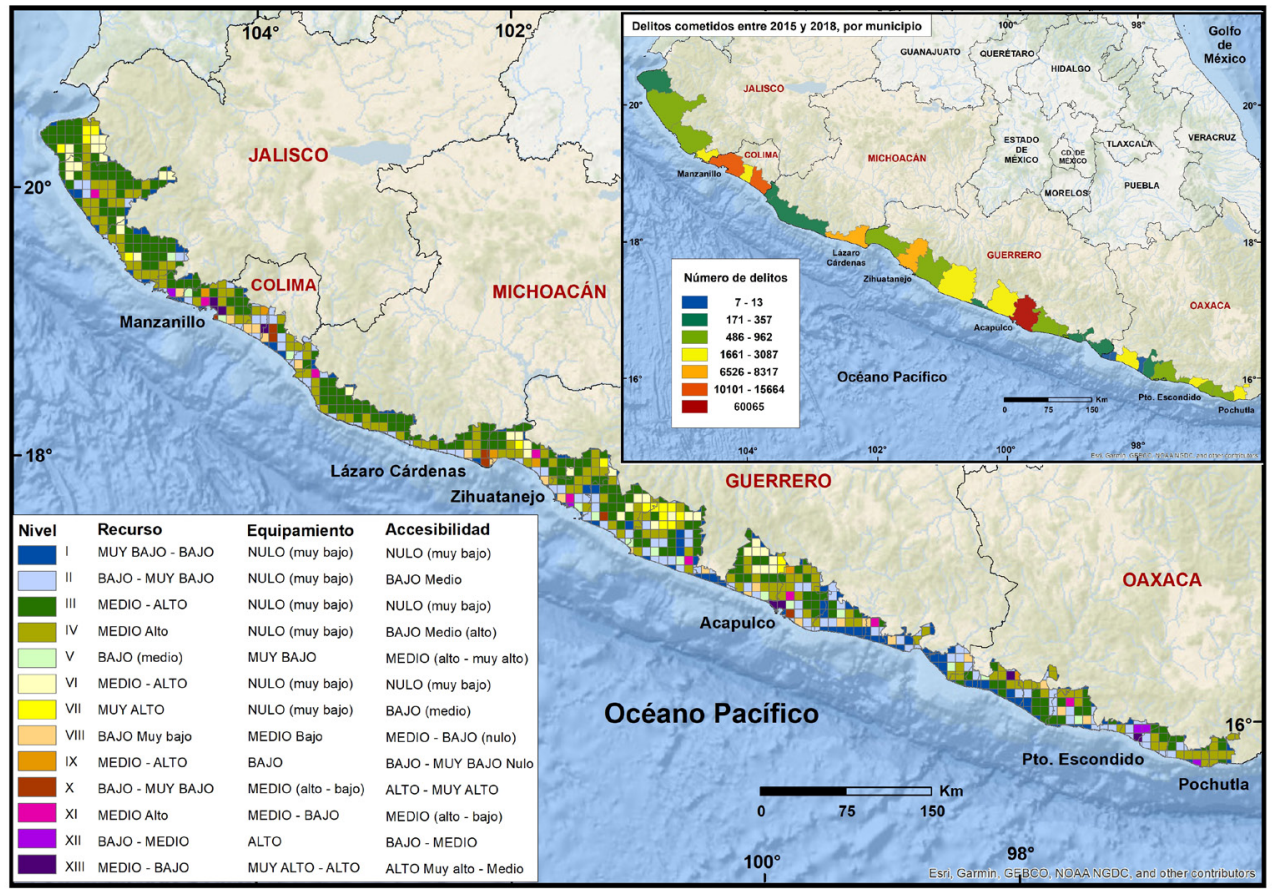

Fuente: Elaborado con base en Cuadros 2-10; Figura 3.

\section{RESULTADOS}

Las valoraciones cualitativas y cuantitativas descritas en la sección anterior proporcionaron información para cada una de las 901 UER que integran la malla geográfica con la que fue dividida la zona de estudio. La representación cartográfica de estos datos revelapatrones espaciales diversos; al respecto, los trece niveles de potencialidad turística (Figura 7) evidencian lo siguiente:

I. Identifica los territorios donde la disponibilidad de recursos naturales, equipamiento y accesibilidad representan los valores muy bajos de toda la costa; en este contexto, desarrollar la actividad turística requeriría una fuerte inversión y trabajo para incentivarlo.

II. Representa zonas con bajos niveles de elementos naturales, la infraestructura se encuentra en valores bajos y aunque la accesibilidad presenta valores medios-bajos, no es suficiente para incentivar el turismo. 
III. Caracteriza lugares donde el relieve abrupto y la diversidad vegetal proporcionan atractivos para el desarrollo de la actividd turística, sin embargo no existe una infraestructura adecuada que atienda a los visitantes.

IV. Agrupa a territorios con estructuras geomorfologicas y asociaciones vegetales muy númerosas, pero al igual que el caso anterior, por falta de infraestuctura turística los recursos naturales no son aprovechados para el desarrollo turístico local.

V. Contiene una riqueza natural propicia para el turismo; en términos de equipamiento hay valores bajos y la accesibilidad se encuentra en niveles medios.

VI. Caracteriza a UER con valores elevados de riqueza natural, pero con infraestructura turística deficiente.

VII. Corresponde a las UER con la mayor riqueza natural y si bien la accesibilidad comienza a ser significativa, es incipiente la infraestructura turística.

VIII. Identifica a UER con condiciones naturales muy heterogeneas y valores bajos en equipamiento y servicios turísticos.

IX. Incluye a UER con un grado de diversidad natural alto pero con deficiente o casi inexistente infraestructura para la atención de los visitantes.

X. Corresponde a UER que presentan grados de diversidad natural bajo, pero con una red carretera consolidada y medios de transporte suficientes para atender a los visitantes. En cuanto a los hoteles, restaurantes, agencias, entre otros, son de baja calidad.

XI. Comprende a lugares con una diversidad natural relativamente importante; su infraestructura turística alcanza valoresmedios y su red carretera está en proceso de consolidarse.

XII. Abarca espacios donde si bien los elementos naturales no son tan diversos y su equipamiento es de baja calidad, es suficiente para la demanda local y para el arribo de un número reducido de turistas; en términos de accesibilidad cuenta con un grado bajo.

XIII. Corresponde a territorios con valores bajos de diversidad cultural y natural, perodonde la infraestructura y la accesibilidad son de buena calidad.

Por otra parte, la Figura 7 muestra que en los municipios costeros de los estados de Guerrero y Jalisco, principalmente, existen numerosos espacios con vocación turística que no corresponde especificamente a los atractivos de litoral. A su vez, en torno a los centros de ocio y recreación de Guerrero y Colima, hay lugares que pueden integrarse como sitios alternativos o como puntos que conformarian corredores turísticos; de lograrse esto, se reduciría la presión de la capacidad de carga turística bajo la que están sujetos Acapulco, Ixtapa - Zihuatanejo, Manzanillo.

Por último, la situación de inseguridad que impera en varios municipios de esta porción del territorio nacional, constituye una limitante para obtener mejores resultados para que los visitantes incursionen en nuevos destinos turísticos, se capten mayores ingresos y los beneficios tengan una mayor cobertura social. Esto ocurre principalmente a lo largo del litoral de los estados de Colima, Michoacán y Guerrero, de tal manera que los municipios costeros de Oaxaca y en menor medida, los de Jalisco, representan espacios en donde pueden formularse proyectos de desarrollo turístico en las comunidades que estén interesadas en esta actividad económica. 


\section{CONCLUSIONES}

El proceso metodológico establecido en este trabajo permitió revelar la dinámica de la actividad turística que se genera en esta porción del territorio mexicano; con ello se proporciona información de carácter espacial que requieren los distintos niveles de gobierno de México en la gestión de recursos que deben canalizase para el desarrollo turístico regional, municipal y local.

Desde una perspectiva territorial, los productos cartográficos obtenidos permiten ponderar los contrastes socioeconómicos que se han generado dentro de la región costera del Pacífico Sur occidental Mexicano; con ello, pueden delimitarse áreas en las que debe contenerse el crecimiento de la actividad turística pues son lugares que detentan elevados niveles de vulnerabilidad ambiental; también es factible identificar lugares cuyo potencial turístico se elevaría a través de estrategias que promuevan un turismo sustentable; además revelan patrones espaciales que avalarían la vinculación regional de la actividad turística.

El mapa referente a la distribución territorial de los niveles de potencialidad turística (Figura 7) detenta diferentes posibilidades de aplicación. En uno de los últimos viajes que se hizo a la zona de estudio, mostró lugares que era necesario visitar para determinar si era factible promover un desarrollo turístico y a partir de ello se trabajó con cuatro cooperativas (tres en el litoral del estado de Oaxaca y una en el de Jalisco) que están interesadas en fortalecer la actividad turística bajo criterios de sustentabilidad ambiental (Reyes et al, 2017).

La sinergía creada entre los procedimientos creados por Leno (1993 y 1993a) y empleados por López (1998) y López et al., (2009) principalmente, para sintetizar información de carácter turístico y el método de la tipificación probabilística que permite diferenciar patrones espaciales de los procesos que se examinan (Juárez, 2000; Propin y Sánchez, 1998 y Sánchez et al., 1999), muestra como la versatilidad de las dos vías metodológicas facilita su aplicación en otros territorios de México y del mundo.

\section{BIBLIOGRAFÍA}

ÁLVAREZ, R. (1987): «Jerarquización de los recursos turísticos», Estudios Turísticos, nº 94, pp. 77-100.

CÉSAR, F. y BELTRÃO, F. (2012): «Potencial del geoturismo y la geodiversidad en la Serra do Cadeado, Paraná, Brasil», Estudios y Perspectivas en Turismo, vol. 21 (2), pp. 322-338.

CONABIO. (2003): Límite Nacional, Escala 1:250000, Comisión Nacional para el Conocimiento y Uso de la Biodiversidad, Extraído de Conjunto de Datos Vectoriales y Toponímias de la carta Topográfica, Instituto Nacional de Estadística, Geografía e Informática (INEGI). México.

CONABIO. (2010): División Política Estatal, Versión 3. Escala 1:250000, Comisión Nacional para el Conocimiento y Uso de la Biodiversidad, Modificado de Conjunto de Datos vectoriales y toponimia de la carta topográfica, Serie III. Instituto Nacional de Estadística, Geografía e Informática (INEGI) (2003-2004), Marco Geoestadístico 
Municipal Versión 4.1 (Censo Económico 2009 - Planeación Censo de Población y Vivienda 2010), Escala 1:250000, INEGI, México.

CONABIO. (2019): Portal de Geoinformación. Sistema Nacional de Información sobre Biodiversidad (SNIB), Comisión Nacional para el Conocimiento y Uso de la Biodiversidad. Disponible enhttp://www.conabio.gob.mx/informacion/gis/, accesado 10 de septiembre de 2019.

CONSTABEL, S. y LIZONDO, C. (1999): «Potencial turístico de la comuna de Timaukel, Tierra del Fuego, Chile», Gestión Turística, no 4, pp. 71-77.

COUTO, V., CORREIA, M. y VELOSO, D. (2007): «Potencialidades espeleoturísticas da área cárstica do município de Luminárias (MG, Brasil)», PASOS. Revista de Turismo y Patrimonio Cultural, vol. 5 (3), pp. 383-390.

DENG, J., KING, B. y BAUER, T. (2002):«Evaluating natural attractions for tourism»,Annals of Tourism Research, vol. 29 (2), pp. 422-438.

DHARMARATNE, G., YEE, F. y WALLING, L. (2000): «Tourism potential for financing protected areas»,Annals of Tourism Research, 27 (3), 590-610.

DIARIO OFICIAL. (2013): Programa Sectorial de Turismo 2013-2018, Publicado el 13 de diciembre de 2013.

DÍAZ, R. (2008): «Potencialidad e integración del "turismo del vino" en un destino de sol y playa: el caso de Tenerife". PASOS. Revista de Turismo y Patrimonio Cultural, vol. 6 (2), pp. 199-212

ENRÍQUEZ, M., OSORIO, M., FRANCO, S., RAMÍREZ, I. y NAVA, G. (2010): «Evaluación multicriterio de los recursos turísticos del Parque Estatal Sierra de Nanchititla, Estado de México», El Periplo Sustentable, n ${ }^{\circ}$ 18, pp. 7-35.

FAÚNDEZ, A. (2013): «Quantification of the Tourism Potential: accounting a component of the territorial wealth», Journal of Technological Possibilism, vol. 2 (4), pp. 1-12.

FRANCO, S. OSORIO, M., NAVA, G. y REGIL, H. (2009): «Evaluación multicriterio de los recursos turísticos. Parque Nacional Nevado de Toluca-México», Estudios y Perspectivas en Turismo, vol. 18 (2), pp. 208-226.

GALLARDO, G. (2013): «Evaluación del potencial turístico de las playas del departamento del Atlántico-Colombia, desde la perspectiva ambiental», Dimensión Empresarial, vol. 11 (2), pp. 62-69.

GARCÍA CASTRO, N. (2007): Cambios En Los Tipos de Asimilación Económica Del Estado de Guanajuato, Entre 1950 y 2000.Tesis de Maestria. División de estudios de posgrado Geografía, Facultad de filosofía y letras, UNAM. Disponible en http://132.248.9.34/pd2008/0623941/0623941.pdf\#search=\%22asimilación económica\%22, accesado el 22 de marzo de 2016.

GARCÍA CASTRO, N. (2011): Los grados de asimilación económica del estado de Guerrero, a fines del siglo XX. Tesis de doctorado. División de estudios de posgrado Geografía, Facultad de filosofía y letras, UNAM. Disponible en http://132.248.9.195/ ptd2012/marzo/0678290/0678290_A1.pdf\#search=\%22asimilación económica\%22, accesado el22 de marzo de 2016.

GARZA, G. y JIMÉNEZ, C. (2007): «Mapa político-territorial de Mesoamérica hacia 1400», Nuevo Atlas Nacional de México, Instituto de Geografía, Universidad Nacional Autónoma de México, México, Hoja: H I. Disponible en http://www.igeograf. 
unam.mx/sigg/publicaciones/atlas/anm-2007/muestra_mapa.php?cual_mapa=H_II_1. jpg, accesado 13 de septiembre de 2018.

GARZA, G., JIMÉNEZ, C. y TOVAR, R. (2007): «Mapa político-territorial de Mesoamérica hacia 1520»,Nuevo Atlas Nacional de México, Instituto de Geografía, Universidad Nacional Autónoma de México, México, Hoja: H II 2. Disponible en http://www.igeograf.unam.mx/sigg/publicaciones/atlas/anm-2007/muestra_mapa.php?cual_mapa=H_ II_2.jpg, accesado el 13 de septiembre de 2018.

GLĂVAN, V. (2006): Potențialul turistic și valorificarea sa. Bucarest, Fundației România de Mâine.

GOBIERNO DE MÉXICO y SECTUR. (2019):Estrategia Nacional de Turismo 2019 - 2024, Presentada en Chetumal, Quintana Roo, el 24 de febrero de 2019. Disponible en http:// amdetur.org.mx/wp-content/uploads/2019/02/Presentaci\%C3\%B3n-Estrategia-Nacionalde-Turismo-21.02.19-FINAL-comprimido.pdf, accesado el 9 de septiembre de 2019.

GOBIERNO DE LA REPÚBLICA. (2013): Plan Nacional de Desarrollo: 2013-2018. México, Gobierno de los Estados Unidos Mexicanos.

GÓMEZ, M.(2004): Métodos y técnicas de la cartografía temática. Temas selectos de Geografía de México.

HONG, S., KIM, J. y KIM, S. (2003): «Implications of potential green tourism development»,Annals of Tourism Research, vol. 30 (2), pp. 323-341.

IELENICZ, M. y COMĂNESCU, L. (2009): România, Potenţial turistic. Ed.Universitară.

INEGI. (2019): Directorio Estadístico Nacional de Unidades Económicas (DENUE), Instituto Nacional de Estadística y Geografía. Disponible en https://www.inegi.org. $\mathrm{mx} / \mathrm{app} / \mathrm{mapa} / \mathrm{denue} /$, accesado 10 de septiembre de 2019.

INEGI. (2019a): Mapas, Instituto Nacional de Estadística y Geografía. Disponible en https://www.inegi.org.mx/datos/?t=0150000000000000, accesado 10 de septiembre de 2019.

JUAN, J., MONROY, J., GASTÓN, J., ANTONIO, X. y BALDERAS, M. (2009): «Los sistemas de barrancos mexicanos, un recurso potencial para el turismo alternativo. El caso de los barrancos del río Calderón, Estado de México», El Periplo Sustentable, $\mathrm{n}^{\mathrm{o}} 17$, pp. 31-54.

JUÁREZ, M. (1999):La Asimilación Económica Del Territorio Costero de México. Universidad Nacional Autónoma de México. Disponible en http://132.248.9.34/ pd1999/271727/271727.pdf\#search=\%22asimilación económica\%22, accesado 3 de agosto de 2015.

JUÁREZ, M. (2000): «Los niveles de asimilación económica de la región costera de México», Investigaciones Geográficas, nº 43, pp. 167-182.

KELLY, M. (1998): «Jordan's potential tourism development», Annals of Tourism Research, vol. 25 (4), pp. 904-918.

LAZO, C., BASTIDAS, M., AGUILAR,F. y CALlE, M. (2017): «La Potencialidad Turística y sus Oportunidades De Emprendimiento. Caso Pasaje», INNOVA Research Journal, vol. 2 (8), pp. 1-21.

LENO, F. (1993): La evaluación de los recursos turísticos. El caso del Canal de Castilla. Tomo II. Facultad de Geografía e Historia. Departamento de Geografía Humana. Editorial de la Universidad Complutense de Madrid. España. 
LENO, F. (1993a): Técnicas de Evaluación del Potencial Turístico. Madrid, Ministerio de Industria, Comercio y Turismo.

LÓPEZ, D.(1998): La ordenación y planificación integrada de los recursos territoriales turísticos: estudio práctico de un espacio de "desarrollo turístico incipiente" el Alto Palancia (Castellón). Castellón de La Plana, Publicacions de la Universitad Jaume I.

LÓPEZ, D., BONFILL, F., BAUTISTA, J. y OUAFAE, A. (2009): «Estudio comparado de la potencialidad de los recursos turísticos en los Parques Naturales de la Sierra de Espadán (España) y Talassemtane (Marruecos)», Cuadernos de Turismo, nº 24, pp. 91-109.

MELIÁN-GONZÁLEZ, A. y GARCÍA-FALCÓN, J. (2003): «Competitive potential of tourism destinations», Annals of Tourism Research, vol. 30 (3), pp. 720-740.

MENDOZA, S. (2001): Niveles de Asimilación Económica Del Estado de Oaxaca.Tesis de Licenciatura, Colegio de Geografía, Universidad Nacional Autónoma de México.

MIKERY, M. y PÉREZ, A. (2014): «Métodos para el análisis del potencial turístico del territorio rural», Revista Mexicana de Ciencias Agrícolas, vol. 5 (SPE 9), pp. 1.7291.740 .

MUNTELE, I. e IAȚU, C. (2006): Geografia turismului. Concepte, metode si forme de manifestare spatio-temporala. Ed. Sedcom Libris. Segunda edición.

NEACSU, N., BALTARETU, A., NEACSU, M. y DRAGUILA, M. (2016): Resurse si destinatii turistice in Romania. Bucarest, Editura Universitara.

ORGAZ, F. y LÓPEZ, T. (2015): «Potencialidades del turismo ornitológico en El Caribe. Un análisis de República Dominicada», PASOS. Revista de Turismo y Patrimonio Cultural, vol. 13 (1), pp. 433-455.

ORTIZ, M. y DE LA LANZA, G. (2006): «Diferenciación del espacio costero de México: un inventario regional», Geografía para el siglo XXI: Serie Textos Universitarios, Universidad Nacional Autónoma de México, México.

PAREDES, C.(2007): «Desarrollo del Poblamiento Español, 1519-1620», Nuevo Atlas Nacional de México, Instituto de Geografía, Universidad Nacional Autónoma de México, México, Hoja: H II 4. Disponible en http:/www.igeograf.unam.mx/sigg/ publicaciones/atlas/anm-2007/muestra_mapa.php?cual_mapa=H_II_4.jpg, accesado 28 de febrero de 2018.

PRATT, S. (2014): «Potential economic contribution of regional tourism development in China: a comparative analysis», International Journal of Tourism Research, vol. 17 (3), pp. 303-312.

PROPIN, E. y SÁNCHEZ, Á. (1998): «Niveles de asimilación económica del estado de Guerrero», Investigaciones Geográficas, n ${ }^{\circ} 37$, pp. 59-70.

RAMÍREZ, J,y LÓPEZ, J. (2012): «Clasificación de las zonas turísticas españolas en función de las características estructurales de la oferta y la demanda», Estudios y Perspectivas en Turismo, vol. 21 (1), pp. 34-51.

REIS, T., DE OLIVEIRA, R., LUIZ, M. y CABRAL, A. (2012):«Potencialidades para a formacão de uma rede de turismo no município de Ouro Preto/MG/Brasil», PASOS. Revista de Turismo y Patrimonio Cultural, vol. 10 (5), pp. 605-618

ROMÁN, G., ZURITA, M., FONSECA, G., CASTILLO, D. y QUEVEDO, L. (2017): «La Potencialidad turística en los proyectos de Turismo Rural Comunitario», European Scientific Journal, vol. 13 (20), pp. 219- 240. 
RYDZIK,A., PRITCHARD, A., MORGAN, N. and SEDGLEY, D. (2013): «The potential of arts-based transformative research», Annals of Tourism Research, vol. 40, pp. 283-305.

SALINAS, E.y SULROCA, F. (2010): «Potencial turístico-recreativo de la agroindustría azucarera cubana»,Estudios y Perspectivas en Turismo, vol. 19 (1), pp. 123-138.

SÁNCHEZ, Á., PROPIN, E. y REYES, O. (1999): «Los niveles de asimilación económica del estado de Coahuila al término del siglo XX», Investigaciones Geográficas, $\mathrm{n}^{\circ} 39$, pp. $159-167$.

SECTUR. (2005): Identificación de Potencialidades Turísticas en Regiones y Municipios. Secretaría de Turismo, Serie de Documentos Técnicos en Competitividad, México.

SEMARNAT.(2002): Informe de la situación del medio ambiente en México. Compendio de estadísticas ambientales 2002. México, Secretaría de Medio Ambiente y Recursos Naturales.

STRAUSS, E. (1972): «Metodología de evaluación de los recursos naturales para la planificación económica y social», Cuadernos del Instituto Latinoamericano de Planificación Económica y Social, Chile, Serie II, Núm. 4.

TAMAYO, N., BENÍTEZ, J. y MOYADO, A. (2007): «Rutas y dinámica comercial durante el siglo XVI»,Nuevo Atlas Nacional de México, Instituto de Geografía, Universidad Nacional Autónoma de México, México, Hoja: H II 8. Disponible en http:// www.igeograf.unam.mx/sigg/publicaciones/atlas/anm-2007/muestra_mapa.php?cual_ mapa=H_II_8.jpg, accesado el 18 de septiembre de 2018.

THÜRMER, R. (1982): «Probabilistische Regionierung-ein Konzept und eine Vorauszetzungen», Wissenschaftliche Mitteilungen, vol. 6, pp. 15-22.

VARJÚ, V., SUVAK, A. y DOMBI, P. (2014): «Geographic Information Systems in the service of alternative tourism-methods with landscape evaluation and target group preference weighting», International Journal of Tourism Research, vol. 16 (5), pp. 496-512. 